\title{
New paroxyclaenid mammals from the early Eocene of the Paris Basin (France) shed light on the origin and evolution of these endemic European cimolestans
}

\author{
Floréal Solé $^{\mathrm{a} *}$, Olivia Plateau ${ }^{\mathrm{b}}$, Kévin Le Verger $^{\mathrm{c}}$ and Alain Phélizon ${ }^{\mathrm{d}}$ \\ ${ }^{a}$ Directorate Earth and History of Life, Palaeobiosphere Evolution Research Unit, Royal Belgian Institute of Natural Sciences, Rue \\ Vautier 29, B-1000 Brussels, Belgium; ${ }^{b}$ Université de Fribourg, Faculté des sciences, Département de géosciences, Chemin du \\ musée 6, Fribourg 1700, Switzerland; ' $C R 2 P-M N H N$, UPMC-Paris 6 (Sorbonne Universités)-Museum National d'Histoire \\ Naturelle, CP 38, 8 rue Buffon, 75005, Paris, France; ${ }^{d}$ Société d'Etude des Sciences Naturelles de Reims, 122 bis, rue du Barbâtre, \\ 51100 Reims, France
}

\begin{abstract}
We present new species of an enigmatic family of mammals, which is endemic to Europe, the Paroxyclaenidae: Merialus bruneti sp. nov., Fratrodon tresvauxi gen. et sp. nov., Paraspaniella gunnelli gen. et sp. nov., and Sororodon tresvauxae gen. et sp. nov. The fossils described come from six localities of the Ypresian of the Paris Basin (France): Pourcy (MP7), Mutigny, Avenay, Condé-en-Brie (MP8+9), Grauves and Prémontré (MP10). They allow the description of three new genera and four new species belonging to the subfamilies Merialinae and Paroxyclaeninae. Two of these new species represent the earliest occurrence of each subfamily. Fossils from Mutigny, Avenay and Condé-enBrie indicate that merialines were more abundant than paroxyclaenines during the Ypresian. Surprisingly, merialines disappeared from the fossil record at the end of the Ypresian - the youngest records are close to MP10 - while the paroxyclaenines were present in Europe until the end of the middle Eocene. Based on comparison with the data presently available for European mammals during the Ypresian, we suggest the existence of two periods of faunal turnover that must be more extensively studied in the future in order to be fully characterized: the 'Intra-Ypresian Mammal Turnover' and the 'Ypresian-Lutetian Mammal Turnover'. Finally, because the oldest paroxyclaenids appear morphologically closer to cimolestids such as Procerberus than to pantolestans, it is suggested that similarities between paroxyclaenids and pantolestans could be due to convergence.
\end{abstract}

http://zoobank.org/urn:1sid:zoobank.org:pub:8A3B21A0-6945-4CE4-975C-402736E92C51

Keywords: Europe; Palaeogene; faunal turnover; Pantolesta

\section{Introduction}

Paroxyclaenidae is an enigmatic family of archaic moderately small placental mammals, which are known only from Europe (Van Valen 1965; Russell \& Godinot 1988). They ranged from the Ypresian (early Eocene) to the Priabonian (late Eocene) (Fig. 1). They have been placed variously by different authors in Carnivora, 'Creodonta', 'Condylarthra' and 'Insectivora', but have been considered members of Pantolesta since the 1970s (McKenna 1975; Russell \& Godinot 1988; McKenna \& Bell 1997; Rose 2006; Koenigswald et al. 2018).

The last extensive and comprehensive review of the paroxyclaenids is that of Russell \& Godinot (1988), in which they described the oldest paroxyclaenid ever found - Merialus martinae from Palette (early Ypresian; France) - and reviewed several paroxyclaenid fossils. In order to describe the evolution of the Paroxyclaenidae, they divided these mammals into two subfamilies: Paroxyclaeninae and Merialinae (Fig. 1).
The dentition of paroxyclaenids consists of four premolars and three molars, resembling in other aspects those of primitive 'condylarths' such as Phenacodus and Hyopsodus, with, for example, enlarged canines and bunodont molars (Lavocat 1958). The dentition is highly specialized, with relatively enlarged posterior premolars and spaced cheek teeth, yet it is primitive in the absence of upper molar hypocones. The molars decrease in size from $\mathrm{M} 1 / \mathrm{m} 1$ to $\mathrm{M} 3 / \mathrm{m} 3$. The $\mathrm{M} 3$ and $\mathrm{m} 3$ are even more reduced in the youngest taxa. A particularity of the dentition of some paroxyclaenids is the tendency for enlargement and molarization of the third and fourth upper and lower premolars, generally exceeding the succeeding molars in size.

As stated by Russell \& Godinot (1988), Paroxyclaeninae is characterized by a particular molarization of the p4: this tooth is notably characterized by the presence of a well-developed metaconid. The second distinctive dental feature of paroxyclaenines is the relatively wide separation of the paraconid and metaconid on the

*Corresponding author. Email: floreal.sole@naturalsciences.be 


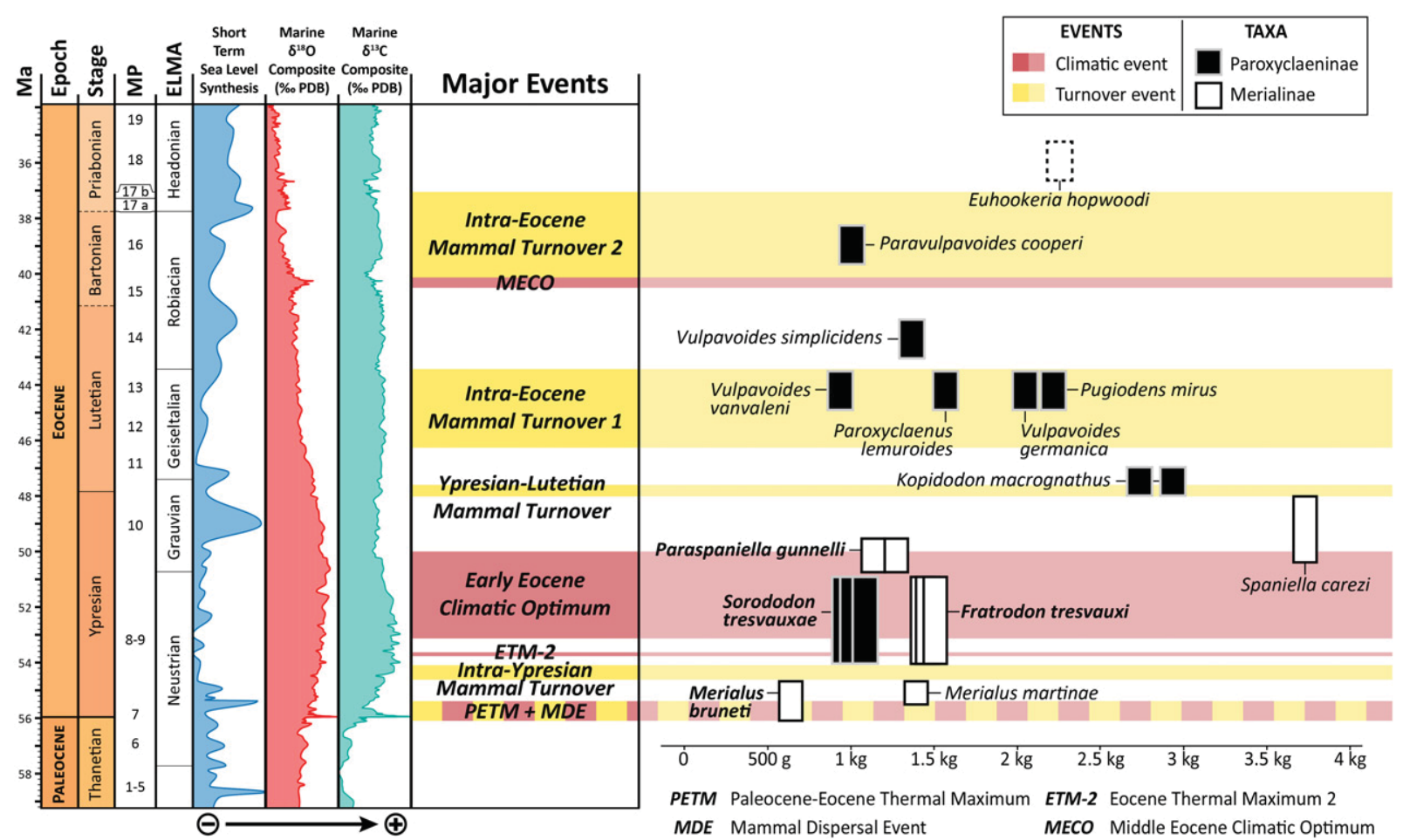

Figure 1. Temporal distribution and the evolution of body mass in paroxyclaenids. The values plotted are the averages of the body masses estimated using the method designed by Legendre (1986). The values are available in the Supplementary material, Files 1 and 2. The four new paroxyclaenids described in the present paper - Merialus bruneti sp. nov., Fratrodon tresvauxi gen. et sp. nov., Paraspaniella gunnelli gen. et sp. nov. and Sorodon tresvauxae gen. et sp. nov. - are in bold. The paroxyclaenid status of Euhookeria hopwoodi is uncertain (see text).

molars (compared to Merialinae). Paroxyclaeninae is the most diverse subfamily in Paroxyclaenidae, with seven species representing five genera: Paroxyclaenus Teilhard de Chardin, 1922; Kopidodon Weitzel, 1933; Vulpavoides Matthes, 1952; Pugiodens Matthes, 1952; and Paravulpavoides Harrison, 2009. Paroxyclaenines first appear in the Lutetian - with Kopidodon from Messel (Germany, reference locality of the reference level MP11 (MP = Mammal Paleogene reference-levels) of the mammalian biochronological scale for the European Palaeogene, BiochroM'97 1997; between 47-48 Myr, Lenz et al. 2015) (Wittich 1902; Weitzel 1933; Koenigswald 1983; Clemens \& Koenigswald 1993; Koenigswald et al. 2018) - and last occur in the Bartonian - represented by Paravulpavoides from Creechbarrow (England, MP16) (Harrison 2009) (Fig. 1). It is worth mentioning that the paroxyclaenine Paroxyclaenus lemuroides, which was considered to be from late Eocene (e.g. Russell \& Godinot 1988), has been identified in Cuzal, a locality that is close to the MP13-MP14 reference levels; consequently, Marandat et al. (1993) considered Paroxyclaenus lemuroides to be Lutetian in age rather than Priabonian.

On the other hand, Merialinae are characterized by the absence of the metaconid on $\mathrm{p} 4$, and by close metaconids and paraconids on molars. Their biostratigraphical range is longer than that of the paroxyclaenines: they are known from the Ypresian to the Priabonian (Fig. 1). However, their evolutionary history is less well known than that of the paroxyclaenine family, as only three monospecific genera have been discovered so far: two in the Ypresian - Merialus martinae from Palette (France; MP7) (Russell \& Godinot 1988) and Spaniella carezi from Barranc de Forals (Spain; MP10) (Crusafont-Pairo \& Russell 1967) - and one in the Priabonian - Euhookeria hopwoodi from the Headon beds (England; MP18) (Cray 1973). Remarkably, merialines are unknown in the Lutetian and Bartonian (Fig. 1).

Finally, it is worth mentioning that Kiinkerishella, which was referred to Paroxyclaeninae by Russell \& Godinot (1988), is now considered a dyspternine pantolestan (Dashzeveg \& Russell 1992; Lucas \& Emry 2004).

As noted by Crusafont-Pairo \& Russell (1967), paroxyclaenids are rare in mammal faunas: each species is represented by one or two individuals. This explains why paroxyclaenids are poorly known. Therefore, the fossils described in the present paper are crucial for understanding the evolution of the paroxyclaenids, and provide new information on their early radiation. 

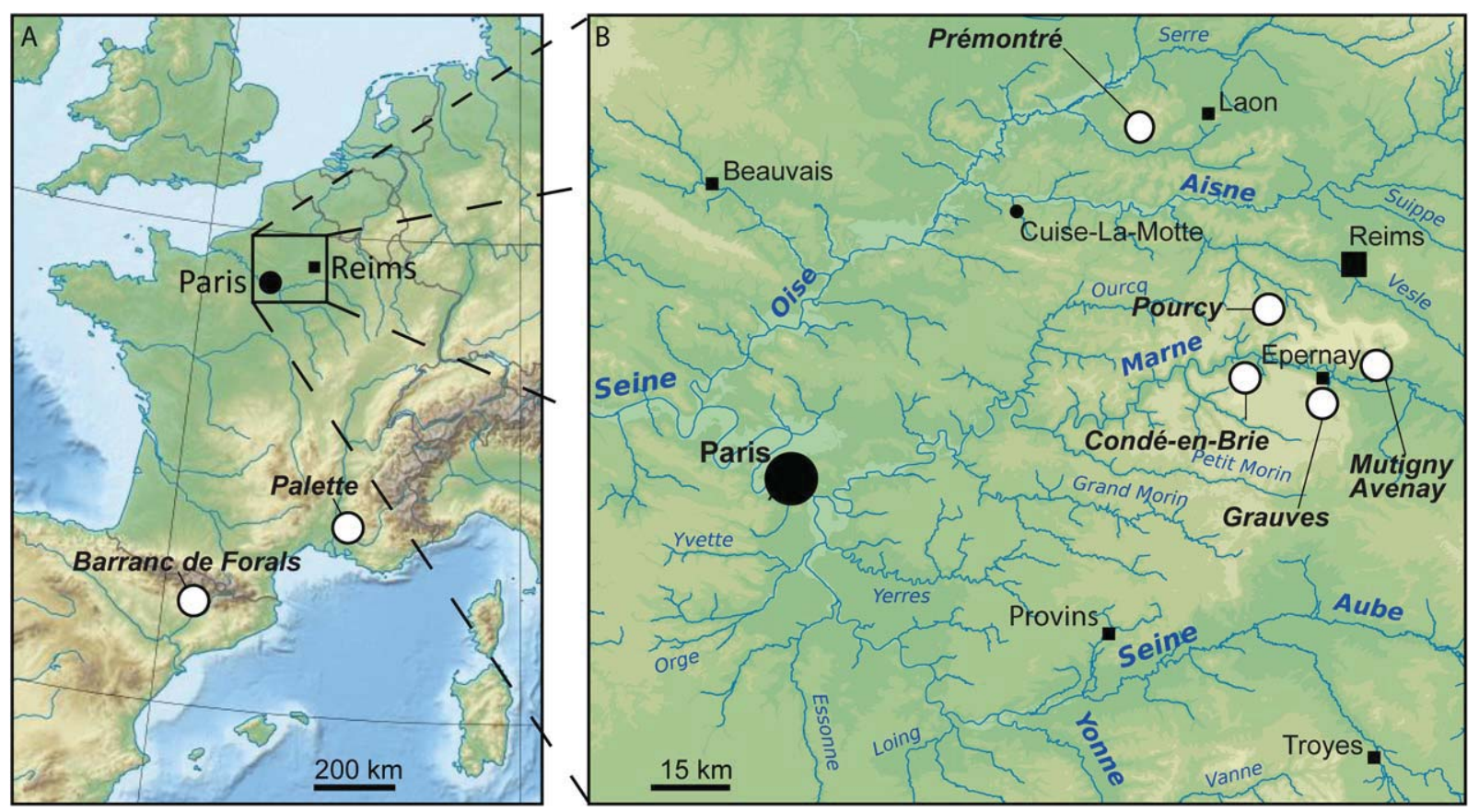

Figure 2. Geographical distribution of paroxyclaenids in Europe during the Ypresian (A) with a close-up on the Paris Basin (B). Merialus martinae: Palette (MP7); Merialus bruneti sp. nov.: Pourcy (MP7); Fratrodon tresvauxi gen. et sp. nov.: Mutigny, Avenay, Condé-en-Brie (MP8 + 9); Paraspaniella gunnelli gen. et sp. nov.: Prémontré, Grauves (MP10); Sorodon tresvauxae gen. et sp. nov.: Mutigny, Avenay, Condé-en-Brie (MP8 + 9); Spaniella carezi: Barranc de Forals (MP10).

Table 1. Age, MP level and PE biozones of the principal localities discussed herein. See text for information concerning ages. MP levels are from BiochroM'97 (1997) and PE biozones from Hooker $(1996,1998)$.

\begin{tabular}{lccc}
\hline Locality & Age (Myr) & MP level & PE biozones \\
\hline Palette & $\sim 55$ & MP7 & - \\
Pourcy & $56-55$ & MP7 & PE III \\
Mutigny & $54-52$ & MP8 +9 & PE IV \\
Avenay & $51-53$ & MP8 +9 & PE V \\
Condé-en-Brie & $\sim 51-53$ & MP8 +9 & PE V \\
Grauves & $50-51$ & MP10 & - \\
Prémontré & $\sim 50.4$ & MP10 & - \\
\hline
\end{tabular}

\section{Material and methods}

\section{Origin of the studied specimens}

The only Ypresian paroxyclaenids well described before the present work were Merialus martinae from Palette (France) and Spaniella carezi from Baranc de Forals (Spain) (Fig. 2). The fossils described in the present paper come from the Ypresian of the Paris Basin (Pourcy, Avenay, Mutigny, Condé-en-Brie, Prémontré and Grauves; Fig. 2). Some of the fossils discovered at Pourcy, Avenay and Mutigny have been described and illustrated previously by Rich (1971).

The locality of Pourcy is considered to be potentially close in age to Abbey Wood (Hooker 1996, 1998); the English locality dates from the early Eocene $(\approx 55.12$
Myr; MP8 + 9) (Hooker 2010). However, the presence at Pourcy of species otherwise known only from beds as old as Dormaal (reference locality of MP7), such as Teilhardimys musculus, together with others shared with younger localities (e.g. Mutigny, Avenay), such as Platychoerops daubrei, suggests that the Pourcy fauna contains taxa of mixed ages, and that the presence of older fossils is an indication of reworked sediments (Cavelier 1987). This leaves its status uncertain (Hooker 2010; see also Aubry et al. 2005 for a discussion concerning the age of deposits from Pourcy). Regardless, the age of the mammal fauna(s) of Pourcy is probably between 56 and 55 Myr (Hooker 1996, 1998). Despite this uncertainty, the locality of Pourcy is considered to be close to the MP7 reference locality (i.e. Dormaal) (BiochroM'97 1997) (Table 1).

Mutigny is younger than Pourcy: it is considered to be close to MP8 + 9 level (Avenay being the reference locality of the level MP8 + 9; BiochroM'97 1997); Mutigny is referred by Hooker $(1996,1998)$ to the PE IV biozone (PE biozone $=$ Paleocene-Eocene biozone) $($ Table 1$)$. The age of Mutigny is still uncertain: it varies between 54 and 52 Myr (Neal 1996; Duprat 1997; Escarguel 1999).

As Mutigny, Avenay and Condé-en-Brie are considered to be close in age to the MP8 +9 reference level, but the two other localities are regarded as younger than Mutigny (Escarguel 1999), Hooker (1996) referred these 
two localities to the PE V biozone (Table 1). Avenay could have an age close to 52-53 Myr (Neal 1996; Escarguel 1999), and a correlation between the mammal faunas of Avenay and the recently described one of Egem (Belgium) suggests an approximate age of 51-52 Myr for Avenay (T. Smith \& Smith 2013, pp. 308-309: "The Egem mammal fauna thus best correlates with the international reference level MP8 +9 of the mammalian biochronological scale for the European Paleogene [... the base of the Egemkapel Clay Member in the middle part of the Tielt Formation that has been dated as middle NP12 (VI) subzone, indicating the early late Ypresian about 51-52 Ma").

The presence at Condé-en-Brie of a species of Lophiaspis, which is unknown in Avenay but well known in the end of the Ypresian, allows placing Condé-en-Brie stratigraphically between Avenay and MP10 localities such as Grauves and Cuis (Louis 1996). However, Escarguel (1999) estimated that Condé-enBrie is 200,000 years older than Avenay (Table 1).

Together, Mutigny, Avenay and Condé-en-Brie cover a period that approximatively corresponds to 54-51 Myr.

Grauves, which is the reference locality of the reference level MP10, belongs to the 'Sables à Unios et Térédines' sensu stricto together with the localities of Cuis, Mancy, Chavot and Monchenot (Laurain et al. 1983; Louis 1996; BiochroM'97 1997) - all of these localities are closely located. The mammalian faunas from these localities are considered to be from the end of the Ypresian (but see Duprat 1997 for a Lutetian age for some of these faunas). Prémontré is considered to be close in age to the localities from the 'Sables à Unios et Térédines' sensu stricto such as Grauves (BiochroM'97 1997; Escarguel 1999). According to Escarguel (1999), Prémontré and Grauves were deposited around 50-51 Myr. Recent study of the microfossil assemblages from the Prémontré Sands allowed an estimate that the deposition of the Prémontré mammal fauna postdated the onset of both NP13 and chron C22r, which are nearly coincident, by about 200-300 kyr, so around 50.4 Myr (Steurbaut et al. 2016) (Table 1).

Finally, it is worth mentioning the case of Palette (south of France) because its fauna provided one of the oldest paroxyclaenids ever discovered. Palette is considered, as is Le Clot, at least 1 million years younger than the MP7 reference locality of Dormaal (Belgium; $\approx 56$ Myr) (Yans et al. 2014), hence close to $55 \mathrm{Myr}$ and to Pourcy (Table 1).

The MNHN houses specimens from Mutigny, Avenay, Pourcy, Condé-en-Brie and Prémontré. The University of Montpellier houses one specimen from Pourcy. Several fossils from Avenay and Condé-en-
Brie, which are described in the present paper, have been found and prepared by one of us (A. Phélizon) and belong to his private collection, but they are accessible for study - to do so, please contact A. Phelizon by email (alain.phelizon@orange.fr). Moreover, casts of these specimens are housed at the Royal Belgium Institute of Natural Sciences (RBINS, Brussels, Belgium: collection RBINS Cast-Vert).

\section{Principal component analysis}

We performed a principal component analysis (PCA) in order to study the morphology of the lower molars of the four new paroxyclaenid species described herein and to identify critera that allow the species to be discriminated from each other. To do so, we performed five measurements on every complete specimen $(n=46)$ : trigonid length, trigonid height, talonid length, talonid height and maximum tooth width. The measurements are available in the Supplementary material, File 1.

The PCA provides an overall analysis of the dataset by quantifying and analysing the gross variability. This is done using conformation ratios (Mosimann \& James 1979; Fabre et al. 2014). For each individual, size was computed as the geometric mean of all measurements, and each measurement was divided by size to obtain the shape ratios. Then the log of this quantity was considered as raw data for subsequent analyses (Claude 2013). These ratios allow calculation of the isometric size by averaging the logarithms. By removing the isometric size from our logarithmic data, only the conformation ratios remain (Fabre et al. 2014). The advantage of this method is that it allows decomposing the shape in size and proportion, as in geometric morphometrics.

All analyses were carried out in reduction of dimensionality, meaning that analyses were carried out on the PCA axes. This allowed the possibility of choosing only a few variables by keeping the multivariate information and eliminating noise (Baylac \& Friess 2005).

\section{Body mass analysis}

In order to analyse the evolution of paroxyclaenid body mass through time, we estimated it for all the species presently known. We used the method developed by Legendre (1986) to estimate the body mass of extinct species; we used the parameters established (1) for all mammals, (2) for large mammals (> 500 g) and (3) for herbivores.

\section{Dental terminology and measurements}

We followed the dental terminology of Szalay (1969). The statistical parameters are the observed range (OR), 


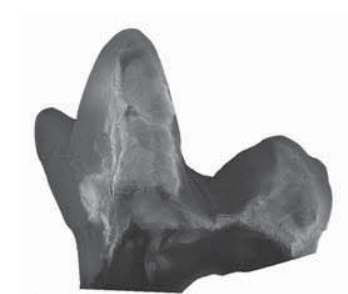

A

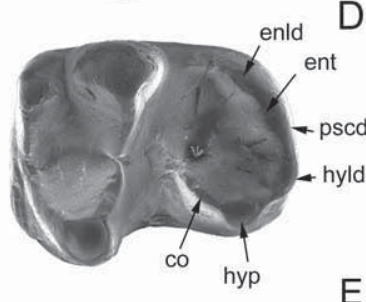

B

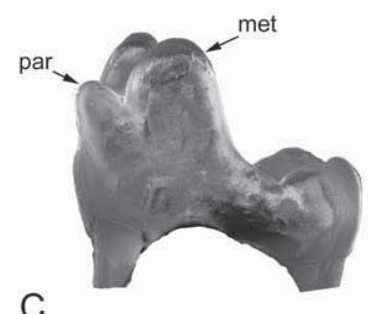

C

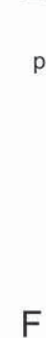

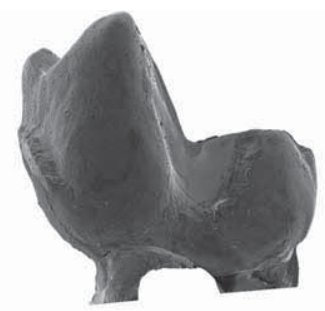
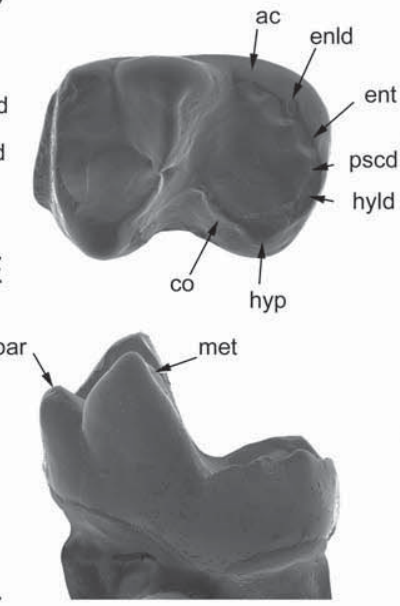

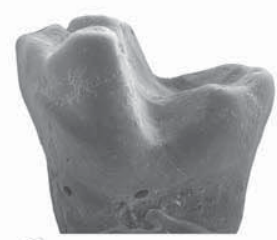

G
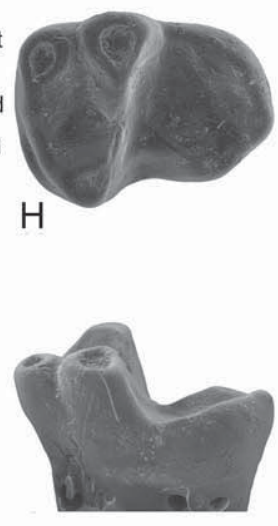
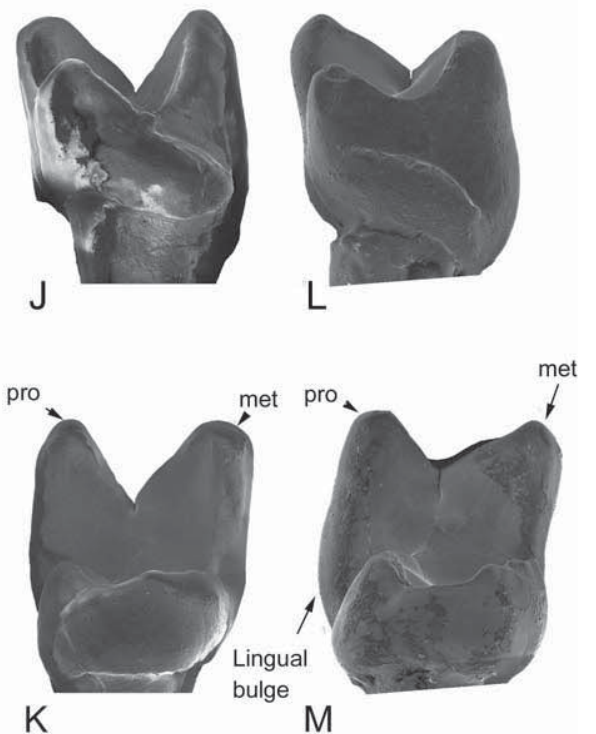

$2 \mathrm{~mm}$ I

Figure 3. Merialus bruneti sp. nov. A-C, MNHN.F.Louis23.Py, left $\mathrm{m} 2$ : A, labial view; B, occlusal view; C, lingual view. D-F, MNHN.F.Louis49.Py (holotype), right $\mathrm{m} 2$; D, labial view; E, occlusal view; F, lingual view; G-I, UM/POY12, left m3: G, labial view; H, occlusal view; I, lingual view. J, K, MNHN.F.Louis23.Py, left $\mathrm{m} 2$ : J, mesial view; K, distal view. L, M, MNHN.F.Louis49.Py (holotype): L, mesial view; M, distal view. Reversed views: C, D, E, I, L, M. Abbreviations: ac, accessory cusp; co, cristid obliqua; enld, entoconulid; ent, entoconid; hyld, hypoconulid; hyp, hypoconid; met, metaconid; par, paraconid; pro, protoconid; psed, postcristid.

mean $(\mathrm{M})$ and standard deviation $(\mathrm{SD})$ - the latter is only estimated when the number of available specimens is equal to or greater than 5.0.

\section{Institutional and collection abbreviations}

Av-Ph: Avenay, Private Collection Phélizon; CB-Ph: Condé-en-Brie, Private Collection Phélizon (France); NHMUK: Natural History Museum (London, United Kingdom); HZM: Harrison Institute collection (Sevenoaks, United Kingdom); MNHN.F.: Muséum National d'Histoire Naturelle (Paris, France), fossil collection; MNHN.F.Av: Avenay (Avenay); MNHN.F.CEB: $\quad$ Condé-en-Brie (MNHN); MNHN.F.Condé Levé: Condé-en-Brie, Collection Levé (MNHN); MNHN.F.Louis.Py, Pourcy, Collection Louis (MNHN); MNHN.F.L-X-Av, Avenay; Collection Louis (MNHN); MNHN.F.L-X-Mut, Mutigny, Collection Louis (MNHN); MNHN.F.MCB: Condé-en-Brie (MNHN); MNHN.F.Mut: Mutigny (MNHN); RBINS: Royal Belgian Institute of Natural Sciences (Brussels, Belgium); RBINS Cast-Vert: Royal Belgian Institute of Natural Sciences (Brussels, Belgium), collection of casts of fossil vertebrates; UM/POY: Université Montpellier (Montpellier, France), from Pourcy (France).

\section{Other abbreviations}

$\mathbf{L}$, length; $\mathbf{n}$, number of specimens; W, width; Lm2/ $\mathbf{L m 3}$, length of the $\mathrm{m} 2$ divided by length of the $\mathrm{m} 3 ; \mathbf{L} /$ W, length divided by width: LTalo/LTrigo, length of the talonid divided by the length of the trigonid.

\section{Systematic palaeontology}

Order Pantolesta McKenna, 1975

Family Paroxyclaenidae Weitzel, 1933

Subfamily Merialinae Russell \& Godinot, 1988

Emended diagnosis (after Russell \& Godinot 1988). Paroxyclaenidae characterized by premolariform premolars (p4 without metaconid) with lingually located paraconid, lower molars with closely situated paraconid and metaconid, and precingulid very weak to absent, subrectangular upper molars in occlusal view. 
Included genera. Spaniella Crusafont-Pairo \& Russell, 1967; Merialus Russell \& Godinot, 1988; Fratrodon gen. nov.; Paraspaniella gen. nov.

Genus Merialus Russell \& Godinot, 1988

Type species. Merialus martinae Russell \& Godinot, 1988.

Other species. Merialus bruneti sp. nov.

Emended diagnosis (after Russell \& Godinot 1988). Merialine that differs from Spaniella by less inflated $\mathrm{p} 2-\mathrm{p} 3$, more ' $\mathrm{V}$ '-shaped (in occlusal view) trigonids of $\mathrm{m} 2$ and $\mathrm{m} 3$, shorter $\mathrm{m} 2$ talonid, and the stronger and more lingually placed paraconid of $\mathrm{m} 3$. Differs from Fratrodon and Paraspaniella by lower talonid cusps, more developed paraconid, slightly more mesially located paraconid, and longer talonid on m3. Differs from Paraspaniella by widely separated paraconid and metaconid apexes.

\section{Merialus bruneti sp. nov.} (Fig. 3)

1971 cf. Paroxyclaenidae; Rich: 61-64, fig. 17 $\mathrm{j}-1$ (partim).

Diagnosis. Differs from Merialus martinae by having smaller teeth $(\sim 10 \%)$. It also differs by widely separated paraconid and metaconid apexes, narrower and lower talonid, and a more pronounced difference in height between the trigonid and talonid on molars.

Derivation of name. Dedicated to $\mathrm{Mr}$ Julien Brunet (1983-) for his help and support to the first author (FS) over many years.

Holotype. MNHN.F.Louis49.Py, right m2.

Referred specimens. MNHN.F.Louis23.Py, left m2; UM/POY12, left m3.

Locality. Pourcy (France), Ypresian (MP7).

Measurements. UM/POY12: $\mathrm{L}=2.63 \mathrm{~mm}, \mathrm{~W}=2.02$ mm. From Rich (1971, table 31): MNHN.F. Louis23.Py: $\mathrm{L}=3 \mathrm{~mm}, \mathrm{~W}=2.1 \mathrm{~mm}$; MNHN.F.L-49-PY: $\mathrm{L}=3.1$ $\mathrm{mm}, \mathrm{W}=2.2 \mathrm{~mm}$.

Description. MNHN.F.Louis49.Py and MNHN.F.Louis23.Py can be considered a possible $\mathrm{m} 2$ based on the closely situated paraconid and metaconid, the size of the $\mathrm{m} 3$ (UM/POY12), and comparison with the proportionally much longer $\mathrm{ml}$ of Merialus martinae.

On the two $\mathrm{m} 2 \mathrm{~s}$, the paraconid is mesiodistally apressed to the metaconid (the trigonid is therefore mesiodistally compressed). These two cusps are poorly separated, but a distinct groove between them is visible in occlusal and lingual views (Fig. 3B, C, E, F). The paraconid, which is lingually located, is lower than the metaconid. The latter cusp is only slightly lower than the protoconid. The protocristid and paracristid are sharp. The paracristid is rather straight, less curved than in Merialus martinae, giving the trigonid an even more distinct ' $\mathrm{V}$ '-shape. A notch is present on the protocristid (Fig. 3K, M), but no notch is distinguishable on the paracristid. The talonid is narrower and lower than the trigonid. The hypoconid is the largest talonid cusp. The hypoconulid and entoconid are very small but well distinguished on MNHN.F.Louis23.Py; they are less individualized on MNHN.F.Louis49.Py. The separation between the hypoconid and hypoconulid is visible on the two specimens. The cristid obliqua is oblique and runs along the posterior wall of the trigonid. The entocristid is high and bears an entoconulid; on MNHN.F.Louis49.Py, one can note the presence of an accessory cusp in front of the entoconulid (Fig. 3E). A notch is present between the entocristid and metaconid. A precingulid is present along the mesial part of the teeth (on both the paraconid and protoconid).

The trigonid on $\mathrm{m} 3$ is mesiodistally compressed. The trigonid basin is closed by an important contact between the base of paraconid and metaconid; the apexes of the cusps are separated by a very small groove, however. The paraconid is poorly projected mesially and is the lowest trigonid cusp. The metaconid and protoconid are similar in height. The trigonid is higher than the talonid. The talonid is narrower than the trigonid. The cristid obliqua is only slightly oblique (distally shifted labially). The entoconid and hypoconid are distinctly higher and larger than the hypoconulid. The hypoconulid is clearly much more distally located than the hypoconid and entoconid (a feature that generally characterized the $\mathrm{m} 3$ of earliest eutherians). The precingulid is less developed than on $\mathrm{m} 2 \mathrm{~s}$. The two roots of UM/POY12 are very close to each other (they are more separated on the two $\mathrm{m} 2 \mathrm{~s})$.

Variability. The two $\mathrm{m} 2$ are very similar in size, but they display several differences. The angle between the protoconid and metaconid is more obtuse in MNHN.F. Louis49.Py (Fig. 3M) than in MNHN.F.Louis23.Py (Fig. 3K). The base of the protoconid of MNHN.F.Louis49.Py shows a bulge at its labial part (Fig. 3M), while the labial part of the protoconid is straighter on MNHN.F.Louis23.Py (Fig. 3K). The paraconid is more reduced on MNHN.F.Louis23.Py and the separation between the paraconid and the metaconid is less visible than on MNHN.F.Louis49.Py. 


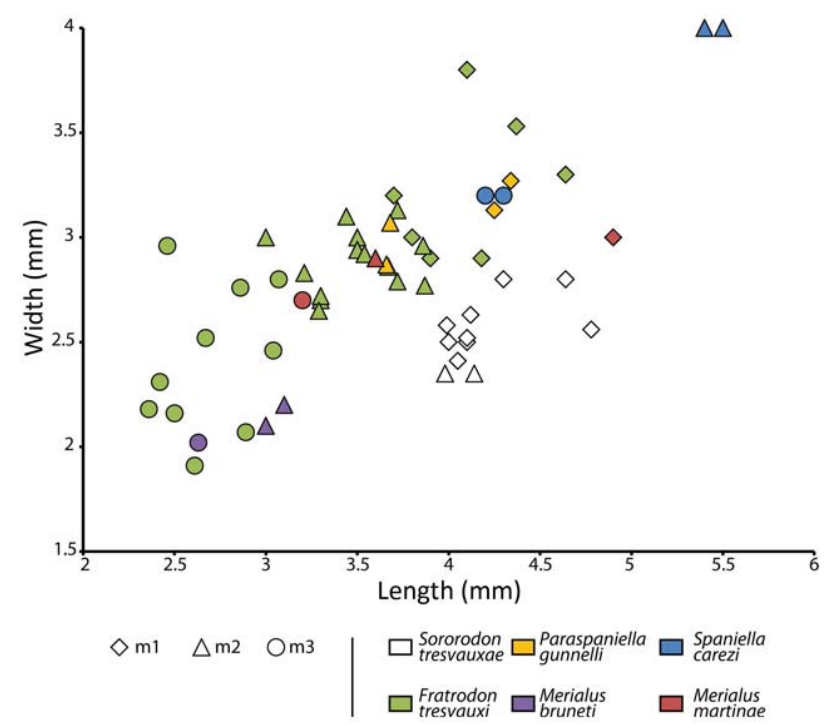

Figure 4. Comparison of the sizes (length $\times$ width) of the lower molars (m1-m3) of Merialus bruneti, M. martinae, Fratrodon tresvauxi, Paraspaniella gunnelli, Sororodon tresvauxae and Spaniella carezi.

The postcristid is rounder on MNHN.F.Louis49.Py (resulting in a wider talonid basin), while it is more oblique on MNHN.F.Louis23.Py. The labial facet of the hypoconid is more inclined (towards the metaconid) on MNHN.F.Louis49.Py than on MNHN.F.Louis23.Py (Fig. 3K, M). The cristid obliqua is more oblique on MNHN.F.Louis23.Py (it runs along the distal facet of the metaconid) than in MNHN.F.Louis49.Py (where it runs towards the notch of the metacristid).

By comparison with younger merialines, (1) this variability is similar (see below) and (2) the combination of the features varies depending on the specimens. Moreover, as for MNHN.F.Louis23.Py and MNHN.F.Louis49.Py, the sizes of the specimens are always very close. Therefore, we believe that these differences represent intra-specific variability only.

Comparison. The three molars referred to the present taxon are from the Ypresian locality of Pourcy. The molars MNHN.F.Louis23.Py and MNHN.F.Louis49.Py were previously described (among others from Avenay and Mutigny) by Rich (1971) and referred to as cf. Paroxyclaenidae. The specimen UM/POY12 is close in size and morphology to the previously described specimens; it is, however, narrower and shorter than the two other molars. Because of the narrow talonid and the distally located hypoconulid, and because UM/POY12 is distinctly smaller than MNHN.F.Louis49.Py and MNHN.F.Louis23.Py, we think that the former tooth is surely an $\mathrm{m} 3$. The two other teeth from Pourcy were considered possible m3s by Rich (1971, table 31), but we believe that they correspond to $\mathrm{m} 2$.
The morphology of the teeth is characterized by a closely appressed paraconid and metaconid and an enlarged talonid. This morphology agrees with that of the molars known for merialines, notably Merialus martinae. The teeth can be distinguished from those of the merialines Spaniella carezi, Fratrodon tresvauxi, and Paraspaniella gunnelli (see below for the description of the latter two species) by their smaller size and the presence of primitive features (compared to younger merialines): presence of a narrow talonid, more pronounced difference in height between the trigonid and talonid, hypoconulid less minute, and entoconid less crestiform. The presence of a deep groove between the paraconid and metaconid clearly resembles Merialus martinae rather than Spaniella and Paraspaniella. Generally, the morphology of the molars is less derived (i.e. with no separation between the paraconid and metaconid) than in the youngest merialines. The fossils from Pourcy differ from the holotype (and sole specimen) of M. martinae in that the talonid that is narrower than the trigonid on $\mathrm{m} 2$ and $\mathrm{m} 3$, the paraconid and metaconid apexes are less closely appressed, and the more pronounced difference in height between the trigonid and talonid on molars. They are also about 10\% smaller (Fig. 4).

As a result, the three isolated molars from Pourcy represent one of the most primitive members of Merialinae ever found. Based on the primitive morphology of the teeth recorded in Pourcy, their similarities with Merialus martinae, as well as their small size, we decided to refer them to a new species: Merialus bruneti sp. nov. This new species provides information on the morphology of the oldest paroxyclaenids, and therefore helps to polarize the evolution of their dental features.

\section{Genus Fratrodon gen. nov.}

Type species. Fratrodon tresvauxi sp. nov.

Diagnosis. As for the type species.

Derivation of name. 'Frater' = Brother (Latin) and 'odon' = tooth (Greek); in reference to the fact that $\mathrm{Mr}$ Frédéric Tresvaux du Fraval and Mrs Marie Tresvaux du Fraval are brother and sister.

Fratrodon tresvauxi sp. nov. (Fig. 5)

1971 cf. Paroxyclaenidae; Rich: 61-64, fig. 17a-i, $\mathrm{m}-\mathrm{o}$ (partim).

1971 cf. Paroxyclaenus; Rich: 58-60, fig. 16a (partim).

Diagnosis. Merialine that differs from Merialus by relatively smaller and more square-shaped lower molars, less difference in height between the trigonid and 
talonid, paraconid close in height to the metaconid, distinctly less ' $V$ '-shaped trigonids (in occlusal view), presence of a metastylid, common presence of cuspulation on the postcristid and entoconid, and shorter talonid on m3. Differs from Spaniella by a less reduced paraconid on $\mathrm{m} 2$ and $\mathrm{m} 3$, more important difference in height between the trigonid and talonid, less reduced $\mathrm{m} 3$, more transversely elongated M2, more developed stylar shelf, parastylar and metastylar areas on M2, more developed paraconule and metaconule on $\mathrm{M} 2$, and a metacrista oriented more distally than labially on M2. Differs from Paraspaniella by having less reduced paraconid, lower entocristid, lower entoconid, deep trigonid and talonid basins, thin precingulid on molars, developed parastylar and metastylar projection, and more individualized metaconule on molars. Differs from all the paroxyclaenids except Paraspaniella by the presence of a preparaconule crista that reaches the parastylar area and ectocingulum.

Derivation of name. Dedicated to $\mathrm{Mr}$ Frédéric Tresvaux du Fraval (1983-) for his help and support to the first author (FS) over many years.

Type locality. Mutigny (Marne, France), Ypresian (MP8+9).

Other localities. Avenay (Marne, France), Ypresian (MP8+9); Condé-en-Brie (Aisne, France), Ypresian (MP8+9).

Holotype. MNHN.F.L-189-Mu, right m1.

Referred specimens from Mutigny (Rich 1971). MNHN.F.Mu5942; right $\mathrm{m1}$; MNHN.F.Mu6272, left m1; MNHN.F.L-190-Mu, right m2; MNHN.F.Mu6168, left m2; MNHN.F.Mu6304, left m2.

Referred specimens from Avenay (Rich 1971). MNHN.F.Av5898, left m1; MNHN.F.Av6759, right m1; MNHN.F.Louis-124-Av, left m1; MNHN.F.Av5002, left m1; MNHN.F.Av5731, right m2; MNHN.F.Av5656, right $\mathrm{m} 2$; MNHN.F.Av5714, left M2.

Newly referred specimens from Avenay. RBINS CastVert-32468-2235 (Av-1920-Ph), left m1; RBINS CastVert-32468-2236 (Av-1813-Ph), right $\mathrm{m} 2$; RBINS Cast-Vert-32468-2237 (Av-806-Ph), right m2; RBINS Cast-Vert-32468-2238 (Av-223-Ph), right m3; RBINS Cast-Vert-32468-2239 (Av-41-Ph), left m3; MNHN.F.Av5816, right m3; MNHN.F.Av628BN, left m3; RBINS Cast-Vert-32468-2240 (Av-1002-Ph), left M1; RBINS Cast-Vert-32468-2241 (Av-2075-Ph), right M1; RBINS Cast-Vert-32468-2242 (Av-1603-Ph), right M2; RBINS Cast-Vert-32468-2243 (Av-2076-Ph), left M2.
Table 2. Length (L) and width (W) data (in $\mathrm{mm}$ ) for the teeth of Fratrodon tresvauxi gen. et sp. nov. from Mutigny (France; MP8 + 9, Ypresian), Avenay (France; MP8 + 9, Ypresian) and Condé-en-Brie (France; MP8 +9, Ypresian). Partially based on Rich (1971, table 31). Abbreviations: M, mean; n, number of teeth; SD, standard deviation.

\begin{tabular}{|c|c|c|c|c|c|}
\hline Locus & & $\mathrm{n}$ & Observed range & $\mathrm{M}$ & SD \\
\hline \multicolumn{6}{|c|}{ Mutigny } \\
\hline \multirow[t]{2}{*}{$\mathrm{m} 1$} & $\mathrm{~L}$ & 3 & $3.7-4.18$ & 3.96 & - \\
\hline & W & 3 & $2.7-3$ & 2.93 & - \\
\hline \multirow[t]{2}{*}{$\mathrm{m} 2$} & $\mathrm{~L}$ & 3 & $3.3-3.7$ & 3.5 & - \\
\hline & $\mathrm{W}$ & 2 & $2.7-3.2$ & 2.95 & - \\
\hline \multicolumn{6}{|l|}{ Avenay } \\
\hline \multirow[t]{2}{*}{ M1 } & $\mathrm{L}$ & 3 & $3.4-4.06$ & 3.81 & - \\
\hline & W & 3 & $4.9-5.44$ & 4.85 & - \\
\hline \multirow[t]{2}{*}{ M2 } & $\mathrm{L}$ & 4 & $2.63-3.39$ & 3.07 & - \\
\hline & W & 4 & $4.26-4.97$ & 4.6 & - \\
\hline \multirow[t]{2}{*}{$\mathrm{m} 1$} & $\mathrm{~L}$ & 3 & $4.1-4.64$ & 4.37 & - \\
\hline & W & 5 & $3.1-3.8$ & 3.43 & 0.26 \\
\hline \multirow[t]{2}{*}{$\mathrm{m} 2$} & $\mathrm{~L}$ & 4 & $3-3.5$ & 3.29 & - \\
\hline & W & 4 & $2.83-3.1$ & 2.98 & - \\
\hline \multirow[t]{2}{*}{$\mathrm{m} 3$} & $\mathrm{~L}$ & 4 & $2.36-2.89$ & 2.68 & - \\
\hline & W & 4 & $1.91-2.76$ & 2.23 & - \\
\hline \multicolumn{6}{|c|}{ Condé-en-Brie } \\
\hline \multirow[t]{2}{*}{ M1 } & $\mathrm{L}$ & 1 & 3.99 & - & - \\
\hline & W & 1 & 5.31 & - & - \\
\hline \multirow{2}{*}{ M2 } & $\mathrm{L}$ & 2 & $3.37-3.56$ & 3.47 & - \\
\hline & W & 2 & $4.35-5.09$ & 4.72 & - \\
\hline \multirow[t]{2}{*}{$\mathrm{m} 2$} & $\mathrm{~L}$ & 9 & $3.29-3.87$ & 3.61 & 0.22 \\
\hline & W & 9 & $2.65-3.13$ & 2.86 & 0.15 \\
\hline \multirow[t]{2}{*}{$\mathrm{m} 3$} & $\mathrm{~L}$ & 6 & $2.42-3.07$ & 2.69 & 0.29 \\
\hline & W & 6 & $2.16-2.96$ & 2.54 & 0.3 \\
\hline
\end{tabular}

Referred specimens from Condé-en-Brie. RBINS Cast-Vert-32468-2244 (CB-633-Ph), left m2?; MNHN.F.Condé.Levé.862, right m2; MNHN.F.CB186, right $\mathrm{m} 2$ ?; MNHN.F.MCB277, right $\mathrm{m} 2$; MNHN.F.MCB0151, left m2; MNHN.F.CB1147, right $\mathrm{m} 2$; MNHN.F.Condé.Levé.1014, right $\mathrm{m} 2$; MNHN.F.CB784, left m2?; MNHN.F.CB974, left m2; MNHN.F.CB189, left m3; MNHN.F.CB15875, right m3; MNHN.F.CEB550, right m3; MNHN.F.CB190, right $\mathrm{m} 3$; RBINS Cast-Vert-32468-2245 (CB-94-Ph), right $\mathrm{m} 3$; RBINS Cast-Vert-32468-2246 (CB-396-Ph), right $\mathrm{m} 3$; MNHN.F.MCB0148, right M1; MNHN.F.CB681, left M2; MNHN.F.CB17, left M2.

Measurements. See Table 2.

Description. Because the M2 and M3 of the species Spaniella carezi are the only upper molars known for merialines, the morphology of the upper molars of Merialinae is poorly known. Therefore, we consider that the upper molars found in Avenay and Condé-en-Brie might correspond to $F$. tresvauxi rather than to $S$. tresvauxae, based on the relative abundance of the lower molars of the merialine Fratrodon tresvauxi compared to those of the paroxyclaenine Sororodon tresvauxae, 
present in the same sites, and based on global morphology and occlusion.

The M1s are triangular in occlusal view: the parastyle and parastylar area are mesially projected, while the metastylar area is shifted distally. The teeth therefore appear symmetrical in this view. The paracone and metacone are widely separated, and the paracone is slightly higher and larger than the metacone. The centrocrista is thin. The stylar shelf is long and the ectoflexus is present. The ectocingulum is defined but not high. The paraconule and metaconule are bulbous. The metaconule is distinctly separated from the protocone; the postprotocrista is thus short. The preprotocrista is long and bears a paraconule. The preparaconule crista joins the parastylar area and ectocingulum. The protocone is large. Its apex is shifted mesially. It is as high as the metacone and the paracone. No lingual cingulum is present.

The M2s are smaller than the M1s, but they are morphologically similar to the latter (e.g. separated paracone and metacone; paracone larger and higher than the metacone; no lingual cingulum; large paraconule and metaconule). The M2 differs from the M1 by the more reduced metastylar area. The reduction of the metastylar area results in an asymmetry of the M2 labial border (in occlusal view). The ectoflexus is shallower than on the M1s but it is still visible.

Nine $\mathrm{m} 1 \mathrm{~s}$ are known. The $\mathrm{m} 1$ is clearly the largest molar of the taxon (Table 2). The trigonid is higher than the talonid and is mesiodistally compressed. The protoconid is the highest trigonid cusp. The metaconid is higher than the paraconid in the oldest specimens (i.e. Mutigny), but they are almost equal in height in the youngest specimens (i.e. Avenay). These two cusps are only slightly lower than the protoconid. The base of the paraconid and metaconid are partially fused; a very shallow groove is distinguishable between the apexes of the two cusps in lingual view. The paraconid is located lingually. The paracristid and protocristid are somewhat acute. The notches on these cristids are barely visible on the specimens from Mutigny, but undistinguishable on the fossils from Avenay. In the fossil samples from Avenay, only MNHN.F.L-124-Av shows a distinct notch on these cristids. Several $\mathrm{m} 1 \mathrm{~s}$ display an additional cusp on the paracristid (Fig. 5B). The talonid is short, as is the trigonid; it is as wide as the trigonid. The hypoconid is the largest and highest talonid cusp, but the entoconid and entocristid are only slightly lower than the hypoconid. The separation between the hypoconid and hypoconulid is clear. The hypoconulid and entoconid are not easily distinguishable: several tiny cusps (i.e. cuspulation) are present on the postcristid and entocristid. The hypoconulid when present is lower than the entoconid and hypoconid. Together the entocristid and postcristid form a posterolingually convex ridge. The talonid basin is lingually closed by the high entocristid and a metastylid. The cristid obliqua is oblique (shifted labially distally). The hypoflexid is deep and distinctly separates the protoconid from the hypoconid. Only a very thin and short precingulid is visible at the base of the paraconid and protoconid (mesiolingual part); it is thinner in the youngest specimens.

The $\mathrm{m} 2 \mathrm{~s}$ are morphologically close to the $\mathrm{m} 1 \mathrm{~s}$ : presence of a metastylid; mesiodistal compression of the trigonid; very closely located paraconid and metaconid; short but wide talonid; cuspulation on the entocristid and postcristid; and a deep hypoflexid. They are, however, smaller and the crown is lower. The paraconid, paracristid and precingulid are more reduced than on $\mathrm{m} 1$. Some doubts persist on the determination of three molars from Condé-en-Brie (MNHN.F.CB784, RBINS Cast-Vert-32468-2244 (CB-633-Ph), MNHN.F.CB186) because these specimens are worn out and partially recall the $\mathrm{m} 1 \mathrm{~s}$; however, their sizes agree with those of the $\mathrm{m} 2 \mathrm{~s}$.

The $\mathrm{m} 3 \mathrm{~s}$ are morphologically similar to the $\mathrm{m} 1 \mathrm{~s}$ and $\mathrm{m} 2 \mathrm{~s}$, but the structure of the teeth is more distorted; one can note the lesser development of the apexes of the trigonid cusps, notably the paraconid. The difference in height between the trigonid and talonid is less pronounced than on $\mathrm{m} 1 \mathrm{~s}$ and $\mathrm{m} 2 \mathrm{~s}$. The talonid is narrower and one can note the distal position of the hypoconulid area regarding the hypoconid and entoconid. The $\mathrm{m} 3 \mathrm{~s}$ also differ by their smaller size (Table 2). The m3s are single-rooted.

Variability. Because we have only very few upper molars, it is difficult to determine the variability of these teeth and to determine the morphological evolution of these teeth. The ectoflexus is absent on RBINS CastVert-32468-2243 (Av-2076-Ph, M2), while it is deep on MNHN.F.CB681 (M2). The intra-specific variability of the ectoflexus is also seen in Kopidodon (T. Lehmann, pers. comm.).

The surface areas of the paraconid and metaconid tend to decrease during their evolution, and so does their separation. The angle of the two parts of the protocristid (i.e. between the protoconid and metaconid) increases through time (i.e. from Mutigny to Condé-en-Brie), while the differences in height between the trigonid cusps and between the talonid and trigonid tend to decrease. The paracristid and protocristid are less acute through time. MNHN.F.L-124-Av (m1) differs in having a large paraconid, a distinct notch on the para- and postcristid, and a small angle between the protoconid and metaconid; these probably represent the reappearance of primitive features. As indicated in the Description 

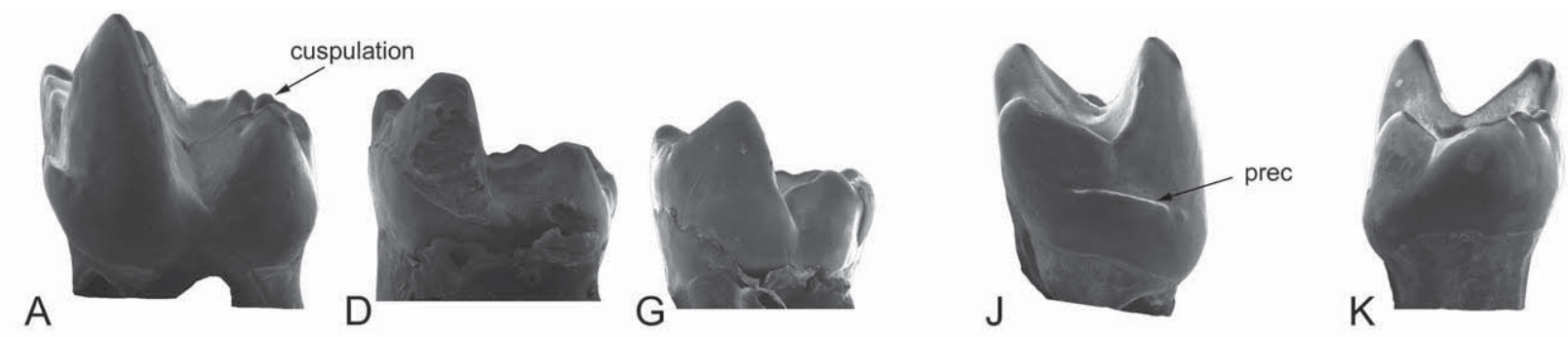
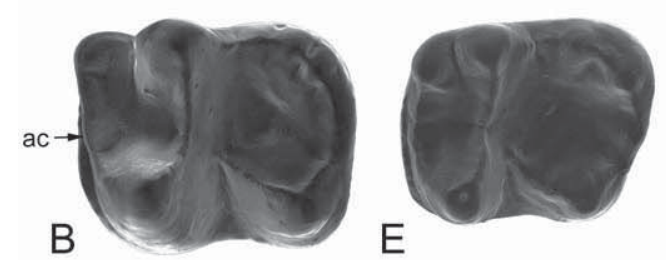

$\mathrm{E}$

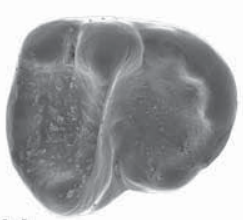

$\mathrm{H}$
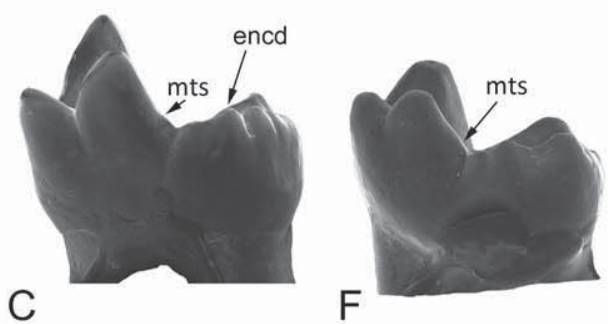

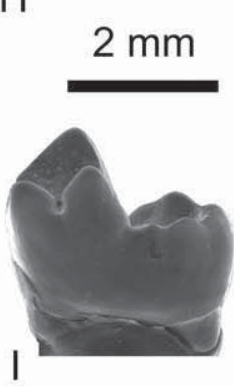

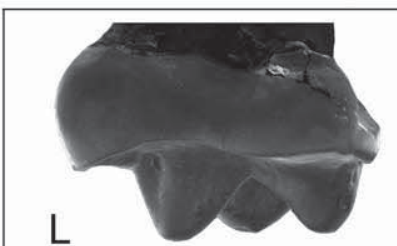

sty

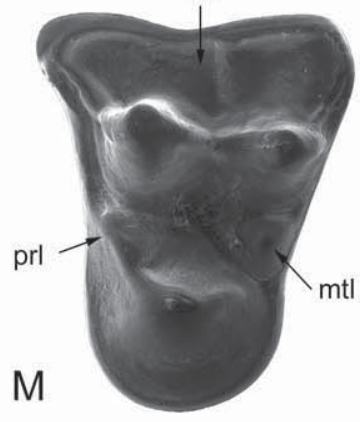

$\mathrm{N}$
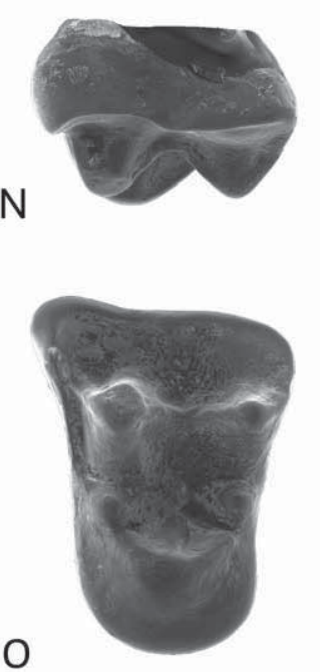

Figure 5. Fratrodon tresvauxi gen. et sp. nov. A-C, MNHN.F.Louis189Mu (holotype), right m1: A, labial view; B, occlusal view; C, lingual view. D-F, MNHN.F.Louis190Mu, right m2: D, labial view; E, occlusal view; F, lingual view. G-I, MNHN.F.CEB 550, right m3; G, labial view; H, occlusal view; I, lingual view. J, K, MNHN.F.Louis189Mu (holotype), right m1: J, mesial view; K, distal view. L, M, RBINS Cast-Vert-32468-2240 (AV-1002-Ph), left M1: L, labial view; M, occlusal view. N, O, MNHN.F.AV5714, left M2: N, labial view; O, occlusal view. Reversed views: A, B, D, E, G, H, J, K. Abbreviations: ac, accessory cusp; encd, entocristid; mts, metastylid; mtl, metaconule; prec, precingulid; prl, paraconule; sty, stylar shelf.

(above), the precingulid on $\mathrm{m} 1$ is more strongly developed on the specimens from Mutigny; it is thinner on the specimens from Avenay and Condé-en-Brie. The entoconid and hypoconid are more or less individualized - and thus distinguishable - depending on the specimens. The most variable lower molar is m3. Moreover, this tooth tends to simplify and decrease in size through time.

Concerning the sizes of the specimens, one can note that the m1s from Avenay are distinctly wider and longer than those from Mutigny (Fig. 6). This could indicate an increase in specimen size through time. However, this trend is not supported by the fossils from Condé-en-Brie, because only $\mathrm{m} 2 \mathrm{~s}$ and $\mathrm{m} 3 \mathrm{~s}$ have been discovered at this locality.

Comparison. The new fossils discovered at Avenay and Condé-en-Brie by one of us (AF) agree in size and morphology with those from Mutigny and Avenay referred to by Rich (1971) as cf. Paroxyclaenidae; they share the mesiodistal compression of the trigonid, the lingual position of the paraconid, the important contact of the paraconid and metaconid, the short but wide talonid, and the cuspulation of the postcristid and entocristid, among other features. This new material improves the description and characterization of this taxon. We agree with some identifications made by Rich (1971), but disagree for MNHN.F.Mu6168, MNHN.F.L-124-Av, MNHN.F.L-189-Mu,

MNHN.F.Av-5002, MNHN.F.5942Mu, MNHN.F.6272Mu (m1s, not m2s), MNHN.F.L-190-Mu and MNHN.F.Av5656 (m2s, not m3s). It is worth mentioning that Rich (1971) actually noted that the teeth he considered possible $\mathrm{m} 3 \mathrm{~s}$ (i.e. MNHN.F.L-190-Mu and MNHN.F.Av5656) are slightly smaller than the $\mathrm{m} 2 \mathrm{~s}$ he identified but were morphologically similar to the $\mathrm{m} 2$ of Spaniella carezi rather than to the $\mathrm{m} 3$ of $S$. carezi. Our new sample confirms his statement; we therefore consider these teeth $\mathrm{m} 2 \mathrm{~s}$.

The lower molars described above share with those of the merialine genera Merialus and Spaniella the paraconid lingually located and closely situated to the metaconid, which is the main feature of this paroxyclaenid 


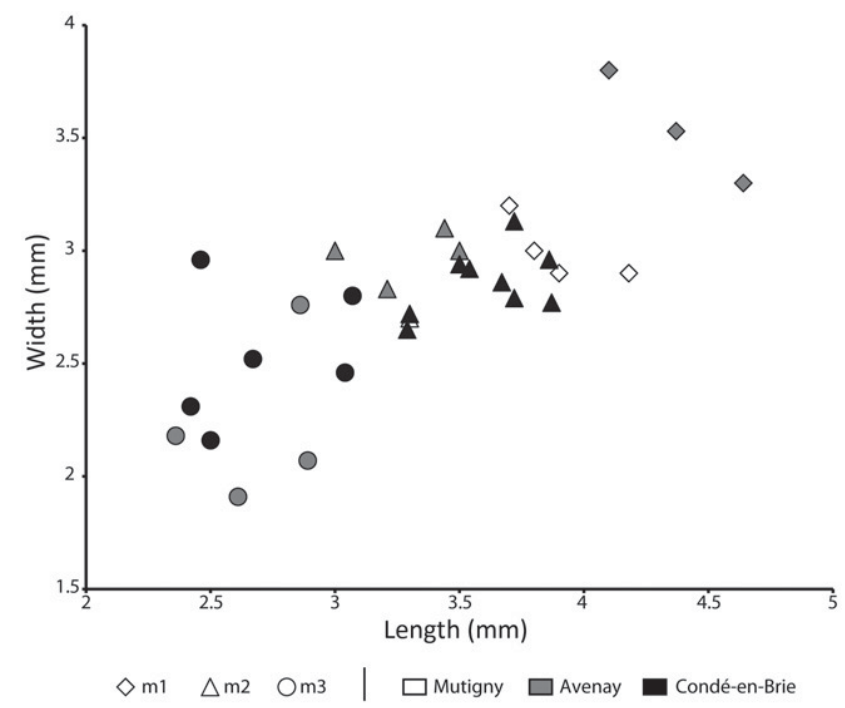

Figure 6. Comparison of the sizes (length $\times$ width) of the lower molars (m1-m3) of Fratrodon tresvauxi from Mutigny, Avenay and Condé-en-Brie.

subfamily (Russell \& Godinot 1988). These features clearly distinguish these fossils from Paroxyclaeninae.

Presently, it is hard to distinguish between the upper molars of paroxyclaenines and merialines; actually, the sole molars identified as belonging to merialines are the M2 and M3 of Spaniella carezi, but their morphology is different from those of paroxyclaenines such as Vulpavoides, Paroxyclaenus and Kopidodon (CrusafontPairo \& Russell 1967). The sole upper molar (MNHN.F.Av5714) from the Paris Basin studied by Rich (1971) was considered an M1 and referred to cf. Paroxyclaenus. Based on the new sample, this tooth is considered an M2 rather than an M1 - the metastylar area is reduced. Rich (1971) considered that MNHN.F.Av5714 could belong to Paroxyclaeninae because he noted the upper molars of this subfamily as well as MNHN.F.Av5714 - differ from those of the merialine Spaniella in having a larger paraconule and broader stylar shelf. Contrary to this conclusion, this tooth is here considered to be an M2 of a merialine species. This is partially based on the higher abundance of merialine lower teeth compared to those of the oldest paroxyclaenine in the MP8 +9 localities (i.e. Sororodon tresvauxae; see below). Furthermore, the M1s referred to Fratrodon tresvauxi differ from the M1 of paroxyclaenines (notably Kopidodon, the oldest taxon represented by upper molars) by the reduction of the ectoflexus, meta- and parastylar areas and stylar shelf, meta- and parastylar areas more labially oriented, and centrally located protocone.

Moreover, the morphology of the M1s and M2s of the presently described taxon recalls the M2 of the merialine Spaniella and the M1s and M2s of the new merialine from Prémontré (Paraspaniella gunnelli; see below). Based on the $\mathrm{L} / \mathrm{W}$ ratio of the $\mathrm{M} 1$ and $\mathrm{M} 2$ (Table 3), one can notice that the M1 and M2 of merialines are less transversally elongated than most of the paroxyclaenines; only Kopidodon and Vulpavoides simplicidens have values close to those of Fratrodon, Paraspaniella and Spaniella. Therefore, the upper molars of merialines are generally more robust than in paroxyclaenines. The upper molars of merialines also generally differ by the features discussed above (i.e. less development and projection of the meta- and parastylar areas, and narrower ectoflexus), but one can argue that the M2 of Fratrodon has only a slightly larger stylar shelf than in Kopidodon. All of these differences confer a more triangular shape to the upper molars of paroxyclaenines compared to those of merialines. However, one can note that the upper molars of the merialines and paroxyclaenines share the important separation between the metacone and paracone, the large paraconule and metaconule, and the wide and long protocone.

The upper molars of Fratrodon tresvauxi differ from those of Spaniella by a more developed paraconule and metaconule on M2, more developed metastylar area, and a metacrista oriented more distally than labially on M2. More importantly, the upper molars of Fratrodon differ from all those of the other paroxyclaenids (except Paraspaniella, see below) by the presence of a preparaconule crista that reaches the parastylar area and ectocingulum.

The fossils referred here to Fratrodon tresvauxi differ from those referred to Merialus by a relatively smaller m3: the ratio $\mathrm{Lm} 2 / \mathrm{Lm} 3$ is 1.13 in Merialus martinae and 1.16 in M. bruneti, while for Fratrodon it is 1.22 in 
Table 3. Ratio of length (L)/width (W) of the DP4, M1, and M2 for several paroxyclaenid species. The minimum, maximum and mean ratios are provided, with the number of specimens following in parentheses.

\begin{tabular}{|c|c|c|c|}
\hline Fratrodon tresvauxi & $\begin{array}{c}\text { DP4 } \\
\text { Avenay } \\
- \\
\text { Condé-en-Brie - }\end{array}$ & $\begin{array}{c}\text { M1 } \\
\text { Avenay } \\
0.73-0.78 / 0.76(2) \\
\text { Condé-en-Brie } 0.75\end{array}$ & $\begin{array}{c}\text { M2 } \\
\text { Avenay } \\
0.65-0.72 / 0.68(3) \\
\text { Condé-en-Brie } \\
0.70-0.78 / 0.74(2)\end{array}$ \\
\hline Paraspaniella gunnelli & 0.92 & $0.67-0.72 / 0.7$ (2) & - \\
\hline Spaniella carezi & - & - & 0.73 \\
\hline Kopidodon macrognathus & 0.98 & $0.76-0.77 / 0.77$ (3) & $0.66-0.71 / 0.67$ (3) \\
\hline Paroxyclaenus lemuroides & - & 0.68 & 0.68 \\
\hline Vulpavoides vanvaleni & - & 0.63 & - \\
\hline Vulpavoides germanica & - & 0.63 & 0.58 \\
\hline Vulpavoides simplicidens & - & 0.75 & 0.7 \\
\hline Paravulpavoides cooperi & - & 0.61 & - \\
\hline
\end{tabular}

Table 4. Ratio of length (L)/width (W) for the $\mathrm{m} 1, \mathrm{~m} 2$ and $\mathrm{m} 3$ for several paroxyclaenid species. The minimum, maximum and mean ratios are provided, with the number of specimens following in parentheses.

\begin{tabular}{|c|c|c|c|}
\hline & $\mathrm{m} 1$ & $\mathrm{~m} 2$ & $\mathrm{~m} 3$ \\
\hline Merialus martinae & 1.63 & 1.24 & 1.19 \\
\hline Merialus bruneti & - & $1.41-1.43 / 1.42(2)$ & 1.3 \\
\hline \multirow[t]{4}{*}{ Fratrodon tresvauxi } & Mutigny & Mutigny & Mutigny \\
\hline & $1.27-1.35 / 1.35$ (3) & $1.16-1.22 / 1.19(2)$ & - \\
\hline & Avenay $1.08-1.41 / 1.24$ (3) & Avenay $1-1.17 / 1.10$ (4) & Avenay $1.04-1.40 / 1.22$ (4) \\
\hline & Condé-en-Brie - & $\begin{array}{c}\text { Condé-en-Brie 1.19-1.40/ } \\
1.34(9)\end{array}$ & $\begin{array}{c}\text { Condé-en-Brie } 0.83-1.24 / \\
1.07(6)\end{array}$ \\
\hline Paraspaniella gunnelli & $1.33-1.36 / 1.35(2)$ & $1.2-1.28 / 1.24(2)$ & - \\
\hline Spaniella carezi & - & $1.35-1.38 / 1.37$ (2) & $1.31-1.34 / 1.33(2)$ \\
\hline \multirow[t]{4}{*}{ Sorodon tresvauxae } & Mutigny & Mutigny & Mutigny - \\
\hline & $1.6-1.64 / 1.62(2)$ & - & Avenay - \\
\hline & Avenay $1.54-1.87 / 1.69$ (3) & Avenay 1.76 & Condé-en-Brie - \\
\hline & $\begin{array}{c}\text { Condé-en-Brie 1.55-1.68 } \\
/ 1.61(4)\end{array}$ & Condé-en-Brie 1.69 & \\
\hline Kopidodon macrognathus & $1.54-1.55 / 1.55(2)$ & $1.28-1.34 / 1.3(2)$ & $1.27-1.31 / 1.29(2)$ \\
\hline Pugiodens mirus & 1.28 & 1.05 & - \\
\hline Paroxyclaenus lemuroides & 1.45 & 1.34 & 1.29 \\
\hline Paravulpavoides cooperi & 1.41 & 1.38 & - \\
\hline
\end{tabular}

Avenay and 1.34 in Condé-en-Brie (based on $\mathrm{m} 2$ and $\mathrm{m} 3$ means) for the new taxon. It is worth remembering that the values of M. bruneti and Fratrodon are based on isolated teeth, while M. martinae is represented by a complete dentary bearing three molars. In Spaniella carezi, the ratio $\mathrm{Lm} 2 / \mathrm{Lm} 3$ equals 1.29 . It is worth noting that this ratio equals 1.22 in the paroxyclaenine Kopidodon (based on $\mathrm{m} 2$ and $\mathrm{m} 3$ means - this value is similar when independently calculating this ratio for each specimen). As a conclusion, the $\mathrm{m} 3$ is importantly reduced in Fratrodon, notably in the sample collected at Condé-en-Brie, the youngest locality where this taxon is recorded. These data clearly indicate a reduction of the last molar; this agrees with the simplification of its morphology.

The taxon recorded at Mutigny, Avenay and Condéen-Brie has slightly more square-shaped molars than Merialus spp. The ratios of $\mathrm{L} / \mathrm{W}$ for $\mathrm{m} 1, \mathrm{~m} 2$ and $\mathrm{m} 3$ of the new species are generally closer to 1 than those of Merialus martinae and M. bruneti (Table 4) - only the ratio for the $\mathrm{m} 3 \mathrm{~s}$ from Avenay and and $\mathrm{m} 2 \mathrm{~s}$ from Condé-en-Brie differ in being higher than that in Merialus spp. (Table 4).

The new fossils differ morphologically from those of Merialus by the reduction of the precingulid, the common cuspulation of the postcristid and entocristid, more closely situated paraconid and metaconid resulting in a distinctly less ' $V$ '-shaped trigonid (in occlusal view), less pronounced groove between the paraconid and metaconid, a development of the metastylid, lower and less developed trigonid on $\mathrm{m} 3$, less mesiodistally elongated talonid on $\mathrm{m} 3$, and a lesser difference in height between the trigonid and talonid on the molars.

The dental features of the lower molars of Fratrodon (e.g. closely approximated paraconid and metaconid, poorly mesiodistally elongated talonid on $\mathrm{m} 3$ ) are 
similarly observed in Spaniella carezi. However, the fossils from Mutigny, Avenay and Condé-en-Brie are smaller than those of $S$. carezi (Fig. 4). The ratio L/W of $\mathrm{m} 2$ and $\mathrm{m} 3$ in Spaniella are higher than in Fratrodon tresvauxi (Table 4). These values, which are also higher than in Merialus martinae, indicate a mesiodistal elongation of the molars in the Spanish paroxyclaenid; however, one can note that these values are close to those of M. bruneti.

Therefore, the lower molars of Fratrodon are more square-shaped than those of most other paroxyclaenids: only Pugiodens mirus have values for the $\mathrm{L} / \mathrm{W}$ ratio close to those of Fratrodon (Table 4). Fratrodon also differs morphologically from the Spanish fossils by a more important difference in height between the trigonid and talonid, less reduced paraconid on molars (notably on $\mathrm{m} 3$ ), the presence of a metastylid, and a higher hypoconid - although the hypoconid is still the highest talonid cusp, the talonid cusps of the molars of $S$. carezi are generally more homogeneous in size (height and wideness). Finally, as noticed by Rich (1971), fossils of Fratrodon from Avenay, Mutigny and Condé-en-Brie differ in having a longer trigonid relative to the talonid; the trigonid is highly mesiodistally compressed in Spaniella. These features are probably distinctive of the oldest merialines. M2 is the only upper molar that can be compared between the two taxa. All of the M2s of Fratrodon differ from the M2 of Spaniella by a slightly more developed stylar shelf, more oblique labial edge on $\mathrm{M} 2$, and the presence of a crest (i.e. the preparaconule crista) between the paraconule and labial cingula. One can note that the values of the ratio $\mathrm{L} / \mathrm{W}$ for the upper molars of the merialines Fratrodon, Spaniella and Paraspaniella, and the paroxyclaenine Kopidodon are close (Table 4).

To conclude, the fossil Fratrodon from the Paris Basin is morphologically different from the other merialines Merialus and Spaniella (e.g. square-shaped lower molars) in spite of sharing common overall morphology. Fratrodon, moreover, displays features that are unknown in the two latter taxa (e.g. the presence of a metastylid). Its discovery thus increases the morphological diversity of the paroxyclaenids and implies the existence of several different morphological 'subgroups' among merialines.

Because of the sum of unique characters, the fossils cannot be referred to one of these genera: we therefore erect a new genus and species, Fratrodon tresvauxi gen. et sp. nov.

Genus Paraspaniella gen. nov.

Type species. Paraspaniella gunnelli sp. nov.
Diagnosis. As for the type species.

Derivation of name. 'Pará' meaning next to (Latin) and Spaniella.

Paraspaniella gunnelli sp. nov. (Fig. 7)

Diagnosis. Merialine that differs from Merialus, Spaniella and Fratrodon by a high entoconid (as high as the hypoconid), a high entocristid, shallow trigonid and talonid basins, and the absence of a precingulid. Differs from Merialus and Fratrodon by much reduced difference in height between the trigonid and talonid, much-reduced paraconid, paracristid and protocristid on lower molars, the absence of a groove between the paraconid and metaconid, and reduced para- and metastylar areas on upper molars. Differs from Spaniella by flat trigonid and talonid basins, less closely located paraconid and metaconid, less reduced paraconid on $\mathrm{m} 2$, trigonid and talonid almost the same in height, higher entoconid, and reduction of the precingulid.

Derivation of name. In memory of Gregg F. Gunnell (1954-2017) who greatly contributed to our knowledge of Cenozoic mammals.

Type locality. Prémontré (Aisne, France), Ypresian (MP10).

Other locality. Grauves (Marne, France), Ypresian (MP10).

Holotype. MNHN.F.SLP-29-PE1327, left m1.

Referred specimens from Prémontré. MNHN.F.SLP29-PE1209, right $\mathrm{m1}$; MNHN.F.SMP-29-PE-1558, left DP4; MNHN.F.SLP-PR-29-2097, right M1; MNHNSLP-29-PE-885, right M1.

Referred specimens from Grauves. MNHN.F.GR7601, right $\mathrm{m} 2$; MNHN.F.GR7874, right $\mathrm{m} 2$.

Measurements. See Table 5.

Description. The DP4 is triangular in occlusal view. The parastyle and postmetacrista are projected mesially and distally, respectively. The stylar shelf is short, the ectocingulum is developed and the ectoflexus is deep. The paracone and metacone are separated and mesiodistally elongated. The apexes are broken, preventing determination of their respective heights. The paraconule and metaconule are well defined and large. The metaconule is larger than the paraconule. The preparaconule crista joins the ectocingulum. A short postparaconule crista is present. The protocone is wide and long; its apex is mesially inclined. No lingual cingulum is visible. 
Table 5. Length (L) and width (W) data (in $\mathrm{mm}$ ) for the teeth of Paraspaniella gunnelli gen. et sp. nov. from Prémontré and Grauves (France; MP10, Ypresian). Abbreviations: M, mean; n, number of teeth.

\begin{tabular}{lllcl}
\hline Locus & & $\mathrm{n}$ & Observed range & $\mathrm{M}$ \\
\hline DP4 & $\mathrm{L}$ & 1 & 3.67 & - \\
& $\mathrm{W}$ & 1 & 4.01 & - \\
$\mathrm{M} 1$ & $\mathrm{~L}$ & 2 & $3.24-3.91$ & 3.58 \\
& $\mathrm{~W}$ & 2 & $4.83-5.44$ & 5.14 \\
$\mathrm{~m} 1$ & $\mathrm{~L}$ & 2 & $4.25-4.34$ & 4.3 \\
& $\mathrm{~W}$ & 2 & $3.13-3.27$ & 3.2 \\
$\mathrm{~m} 2$ & $\mathrm{~L}$ & 2 & $3.66-3.68$ & 3.67 \\
& $\mathrm{~W}$ & 2 & $2.87-3.07$ & 2.97 \\
\hline
\end{tabular}

We consider that the two upper molars from Prémonté (MNHN.F.SLP-PR-29-2097 and MNHN-SLP29-PE-885) are M1s based on their sizes. The M1 is subrectangular in occlusal view. They are completely separated and linked by a thin centrocrista. The paracone is distinctly larger and higher than the metacone. The stylar shelf is short, notably labially to the paracone; the ectocingulum is high and covered by numerous small cuspules. The para- and metastylar areas are much reduced. The ectoflexus is distinguishable on MNHN.F.SLP-29-PE-885, but absent on MNHN.F.SLPPR-29-2097. The protocone is large and mesially inclined (as a result the preprotocrista is shorter than the postprotocrista). The protocone is almost as high as the paracone and metacone. The metaconule and paraconule are high and well defined; they are close to the paracone and metacone, respectively. The paraconule is linked to the ectocingulum by the preparaconule crista. No lingual cingulum is visible.

Two $\mathrm{m} 1 \mathrm{~s}$ are known from Prémontré and two $\mathrm{m} 2 \mathrm{~s}$ from Grauves. The $\mathrm{m} 1 \mathrm{~s}$ are clearly longer than the $\mathrm{m} 2 \mathrm{~s}$ (Table 5); moreover, they display a larger paraconid. The trigonid is only slightly higher than the talonid. The trigonid is mesiodistally compressed. The protoconid is the highest trigonid cusp, but only very slightly. The paraconid is lower than the metaconid. The paraconid is lingually located. The para- and postcristid are only slightly acute. There is no groove between the paraconid and metaconid. The trigonid basin is almost flat. The paracristid is mesially curved (visible in occlusal view); a distinguishable additional cusp is present on this cristid on MNHN.F.SLP-29-PE1209; it is less prominent on MNHN.F.SLP-29-PE1327 (Fig. 7B). No notch is present on either the protocristid or the paracristid. The talonid is short; it is as wide as the trigonid. The hypoconid and entoconid are the largest and highest talonid cusps; they are almost equal in height. The hypoconulid is present but less developed than the two other cusps. The cristid obliqua is oblique (distally shifted labially). The cristid obliqua and entocristid are high, closing the talonid basin labially and lingually. The talonid basin is shallow, a metastylid is present and the precingulid is absent. The hypoflexid is deep and distinctly separates the protoconid from the hypoconid.

The $\mathrm{m} 2 \mathrm{~s}$ are morphologically similar to the $\mathrm{m} 1 \mathrm{~s}$ : they display the mesiodistal compression of the trigonid, the shallow trigonid and talonid basins, the closely located paraconid and metaconid, the short and wide talonid, the high entoconid and hypoconid, and the deep hypoflexid. They are, however, smaller than $\mathrm{m} 1 \mathrm{~s}$ and differ in their lower trigonid.

Variability. The sample is small (seven isolated teeth representing four loci) but provides information concerning variability within this species. MNHN-SLP-29-PE885 (M1) shows a deeper ectoflexus than MNHN.F.SLP-PR-29-2097 (M1). MNHN.F.SLP-29PE1209 (m1) has a more distinct accessory cusp on the paracristid. MNHN.F.GR7874 (m2) has a more mesiodistally compressed trigonid; it also appears more transversely enlarged (a variation already noted in Fratrodon tresvauxi). A tiny precingulid is visible on GR7601 (m2) but is less developed than in specimens of F. tresvauxi from Avenay, Mutigny and Condé-en-Brie. To conclude, this variation recalls that observed in F. tresvauxi and Merialus bruneti.

Comparison. The presence of a DP4 is interesting because the deciduous molars of paroxyclaenids are rare: this type of tooth is currently known only for Kopidodon and (more doubtfully) Paravulpavoides (Koenigswald 1983; Hooker 1986; Harrison 2009). The tooth is similar to, but smaller than, the DP4 of Kopidodon (Koenigswald 1983, fig. 4). However, the sole presence of merialine teeth and the dimensions of this tooth, which fit with the permanent molars, lead us to consider this tooth as merialine. It is worth mentioning that the presence of deciduous teeth is common in artiodactyls, rodents and pantolestids at Prémontré (Sudre \& Erfurt 1996; Escarguel 1999; R. Smith 2001).

There are similarities between the M2 of Kopidodon and the M1s of the new taxon described herein (MNHN.F.SLP-PR-29-2097 and MNHN-SLP-29-PE885): a reduced stylar shelf, reduced para- and metastylar areas, and subrectangular morphology. However, compared to Kopidodon, the upper molars are close in size to the DP4 (3.24 and $3.91 \mathrm{~mm} \mathrm{vs} 3.67 \mathrm{~mm})$; in Kopidodon the M1 is as long as the DP4, while the M2 is distinctly shorter than the DP4. When comparing the M1s from Prémontré and the M1 of Kopidodon, the upper molars from Prémontré differ by reduced paraand metastylar areas, a reduced metacone with respect to the paracone, and the absence of an ectoflexus. 

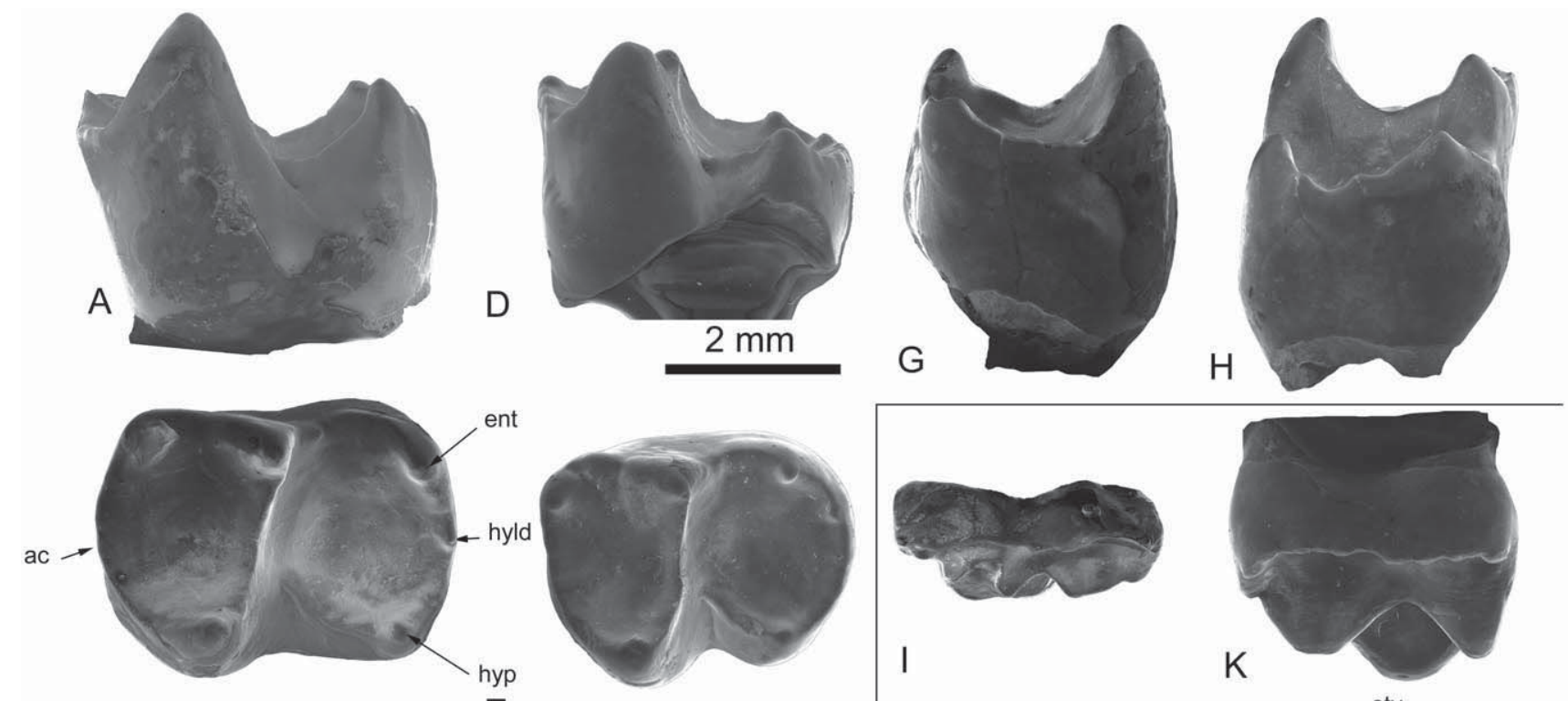

B

E

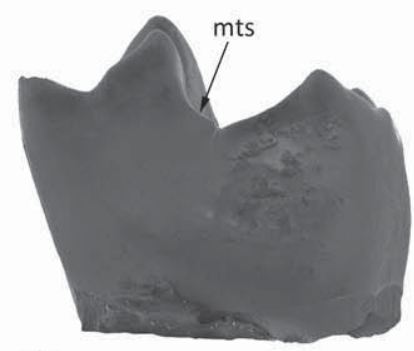

C

F
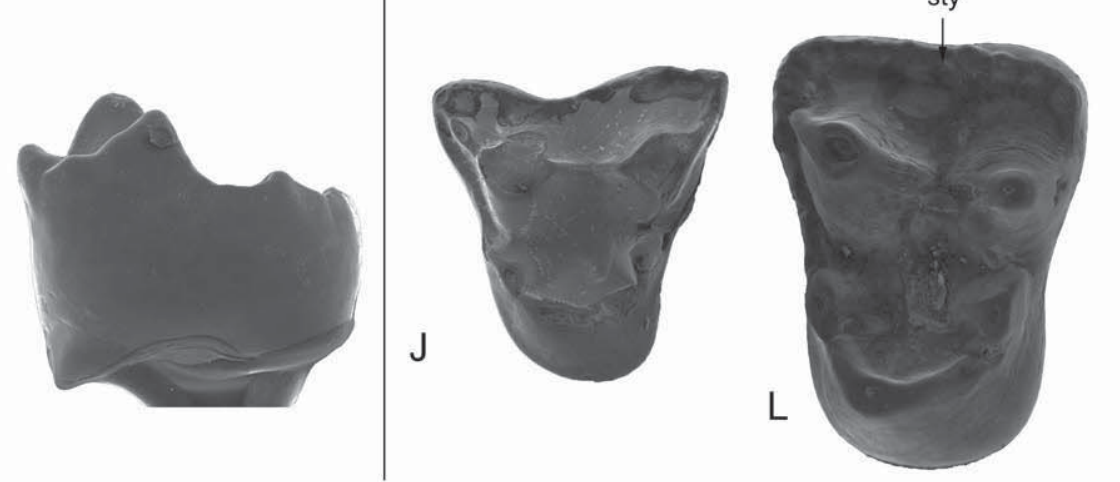

Figure 7. Paraspaniella gunnelli gen. et sp. nov. A-C, MNHN.F.SLP-29-PE 1327 (holotype), left m1: A, labial view; B, occlusal view; C, lingual view. D-F, MNHN.F.GR 7601, right m2: D, labial view; E, occlusal view; F, lingual view. G, H, MNHN.F.SLP29-PE 1327 (holotype), left m1: G, mesial view; H, distal view. I, J, MNHN.F.SLP-29-PE 1558, left DP4: I, labial view; J, occlusal view. K, L, MNHN.F.SLP-PR-29 2097, right M1: K, labial view; L, occlusal view. Reversed views: C, D, E, K, L. Abbreviations: ac, accessory cusp; ent, entoconid; hyp, hypoconid; hyld, hypoconulid; mts, metastylid; sty, stylar shelf.

The reduction of the para- and metastylar areas on MNHN.F.SLP-PR-29-2097 and MNHN-SLP-29-PE-885 agrees with the transversal orientation of the para- and protocristid on the m1s discovered at Prémontré. The reduction of the metacone on the upper molars also fits with the poor development of wear facet 4 on the m1s (compared to the large wear facets 1 and 3). Consequently, we consider that the upper and lower teeth discovered at Prémontré and Grauves belong to the same taxon.

The fossils discovered at Prémontré and Grauves differ from those of Fratrodon tresvauxi from Mutigny, Avenay and Condé-en-Brie by a lesser difference in height between the trigonid and talonid. In this regard, it recalls the Spanish species Spaniella carezi. No cuspulation is observed on the molars from Prémontré and Grauves, unlike in those of $F$. tresvauxi; on the contrary, the entoconid is well individualized and is as high as the hypoconid; moreover, the entoconid and hypoconid are close in height to the paraconid and metaconid on the $\mathrm{m} 1$. The entoconulid, present on the molars of $F$. tresvauxi, is absent on the molars from Prémontré and the trigonid and talonid basins are shallower on the molars of the new taxon. The latter feature represents a tendency that is visible in few specimens of $F$. tresvauxi. The upper molars of the new taxon also differ importantly from those of $F$. tresvauxi by the reduction of the metastylar and parastylar areas, and the reduction of the separation between the metaconule and protocone. All of the features that characterize the lower molars also distinguish the new taxon from M. martinae and M. bruneti.

Some of these features are present in Spaniella (e.g. reduced and lingually located paraconid, reduced para- 
and metastylar areas, subrectangular upper molars). However, the fossils from Prémontré differ from the Spanish merialine by the flat trigonid and talonid basins, the less closely located paraconid and metaconid, the less reduced paraconid on $\mathrm{m} 2$, the trigonid and talonid being similar in height, the higher entoconid, and the reduction of the precingulid; moreover, the trigonid basin seems longer on the $\mathrm{m} 2 \mathrm{~s}$ from Grauves than in those from Barranc de Forals (MP10).

The teeth from Prémontré and Grauves also seem to share with those from Spain a less square morphology in comparison with specimens of $F$. tresvauxi (Table 4). However, the $\mathrm{L} / \mathrm{W}$ values for the $\mathrm{m} 2 \mathrm{~s}$ (the only values that can be compared between the two species) are lower than those of Spaniella (Table 4). It is worth noting that the $\mathrm{L} / \mathrm{W}$ values for the $\mathrm{m} 2 \mathrm{~s}$ from Grauves are close to that of Merialus martinae (Table 4).

\section{Subfamily Paroxyclaeninae Weitzel, 1933 Genus Sororodon gen. nov.}

Type species. Sororodon tresvauxae sp. nov.

Diagnosis. As for the type species.

Derivation of name. 'Soror' $=$ sister (Latin) and 'odon' $=$ tooth (Greek); in reference to the fact that $\mathrm{Mr}$ Frédéric Tresvaux du Fraval and Mrs Marie Tresvaux du Fraval are brother and sister.

\section{Sororodon tresvauxae sp. nov.}

(Fig. 8)

1971 cf. Paroxyclaenus; Rich: 58-61, fig. 16b-e (partim).

Diagnosis. Differs from other paroxyclaenines (Kopidodon, Vulpavoides, Paroxyclaenus, Paravulpavoides) in possessing a more mesially located paraconid (resulting in a greater distance between the paraconid and metaconid) and a wider talonid on molars.

Derivation of name. Dedicated to Mrs Marie Tresvaux du Fraval (1990-) for her help and support to the first author (FS) over many years.

Type locality. Mutigny (Marne, France), Ypresian (MP8+9).

Other localities. Avenay (Marne, France), Ypresian (MP8+9); Condé-en-Brie (Aisne, France), Ypresian (MP8+9).

Holotype. MNHN.F.CEB 521, right $\mathrm{m} 1$.

Referred specimens from Mutigny (Rich 1971). MNHN.F.Mu5947, left m1; MNHN.F.Mu6385, right m1.
Table 6. Length (L) and width (W) data (in $\mathrm{mm}$ ) for the teeth of Sororodon tresvauxae gen. et sp. nov. from Mutigny (France; MP8 + 9, Ypresian), Avenay (France; MP8 + 9, Ypresian) and Condé-en-Brie (France; MP8 +9, Ypresian). Partially based on Rich (1971, table 30). Abbreviations: M, mean; $\mathbf{n}$, number of teeth.

\begin{tabular}{lcccc}
\hline Locus & & $\mathrm{n}$ & Observed range & $\mathrm{M}$ \\
\hline Mutigny & & & & \\
$\mathrm{m} 1$ & $\mathrm{~L}$ & 2 & $4-4.1$ & 4.05 \\
& $\mathrm{~W}$ & 2 & 2.5 & 2.5 \\
Avenay & & & & \\
$\mathrm{m} 1$ & $\mathrm{~L}$ & 3 & $4.3-4.78$ & 4.57 \\
& $\mathrm{~W}$ & 3 & $2.56-2.8$ & 2.72 \\
$\mathrm{~m} 2$ & $\mathrm{~L}$ & 1 & 4.14 & - \\
& $\mathrm{W}$ & 1 & 2.35 & - \\
Condé-en-Brie & & & \\
$\mathrm{m} 1$ & $\mathrm{~L}$ & 4 & $3.99-4.12$ & 4.07 \\
& $\mathrm{~W}$ & 4 & $2.41-2.63$ & 2.54 \\
$\mathrm{~m} 2$ & $\mathrm{~L}$ & & 3.98 & - \\
& $\mathrm{W}$ & & 2.35 & - \\
\hline
\end{tabular}

Referred specimens from Avenay (Rich 1971). MNHN.F.Av5909, right m1.

Referred specimens from Avenay. MNHN.F.Av7712, left m1; RBINS Cast-Vert-32468-2247 (Av-1000-Ph), right $\mathrm{m} 1$; MNHN.F.Av4561, left m2.

Referred specimens from Condé-en-Brie. MNHN.F.CEB525, left m1?; MNHN.F.Levé.Condé.924, right $\mathrm{m} 1$; ; MNHN.F.MCB365, right $\mathrm{m} 1$; RBINS CastVert-32468-2248 (CB-12-Ph), right m2.

Measurements. See Table 6.

Description. The $\mathrm{m} 1$ is characterized by a mesiodistally elongated trigonid and a wide separation between the paraconid and metaconid. The paraconid is mesiolingually located; the paracristid is oblique and convex. The paraconid is smaller than the metaconid; the protoconid is the highest cusp of the trigonid. The metaconid is more distally located than the protoconid. Notches are present on the para- and protocristid. The metaconid is mesiodistally elongated in lingual view. A metastylid is present; its size varies from one specimen to another. A small cusp is present on the postparacristid of several specimens. The talonid is shorter than the trigonid (Table 7), but is as wide as the latter structure. The hypoconid is large. The entoconid and hypoconulid are not distinguishable on all the specimens because they are replaced by a very thin cuspulation on the postcristid and entocristid. The postcristid and entocristid are fused and are more or less convex depending on the specimen. The cristid obliqua is strongly oblique. The hypoflexid is deep. The talonid basin is closed lingually by a high entocristid. A notch is sometimes present between the entocristid and metastylid. A faint precingulid is visible 
Table 7. Ratio of talonid length (LTalo)/trigonid length (LTrigo) of the $\mathrm{m} 1, \mathrm{~m} 2$ and $\mathrm{m} 3$ for several paroxyclaenid species. The minimum, maximum and mean ratios are provided, with the number of specimens following in parentheses.

\begin{tabular}{lccc}
\hline & $\mathrm{m} 1$ & $\mathrm{~m} 2$ & $\mathrm{~m} 3$ \\
\hline Merialus bruneti & - & $0.89-1.17 / 1.03(2)$ & - \\
Fratrodon tresvauxi & $0.91-1.19 / 1.04(6)$ & $0.73-1.36 / 1.05(16)$ & $0.55-1.1 / 0.95(10)$ \\
Paraspaniella gunnelli & $0.58-0.87 / 0.71(2)$ & $0.91-0.99 / 0.95(2)$ & - \\
Sororodon tresvauxae & $0.50-0.93 / 0.71(9)$ & $0.67-0.85 / 0.76(2)$ & - \\
\hline
\end{tabular}
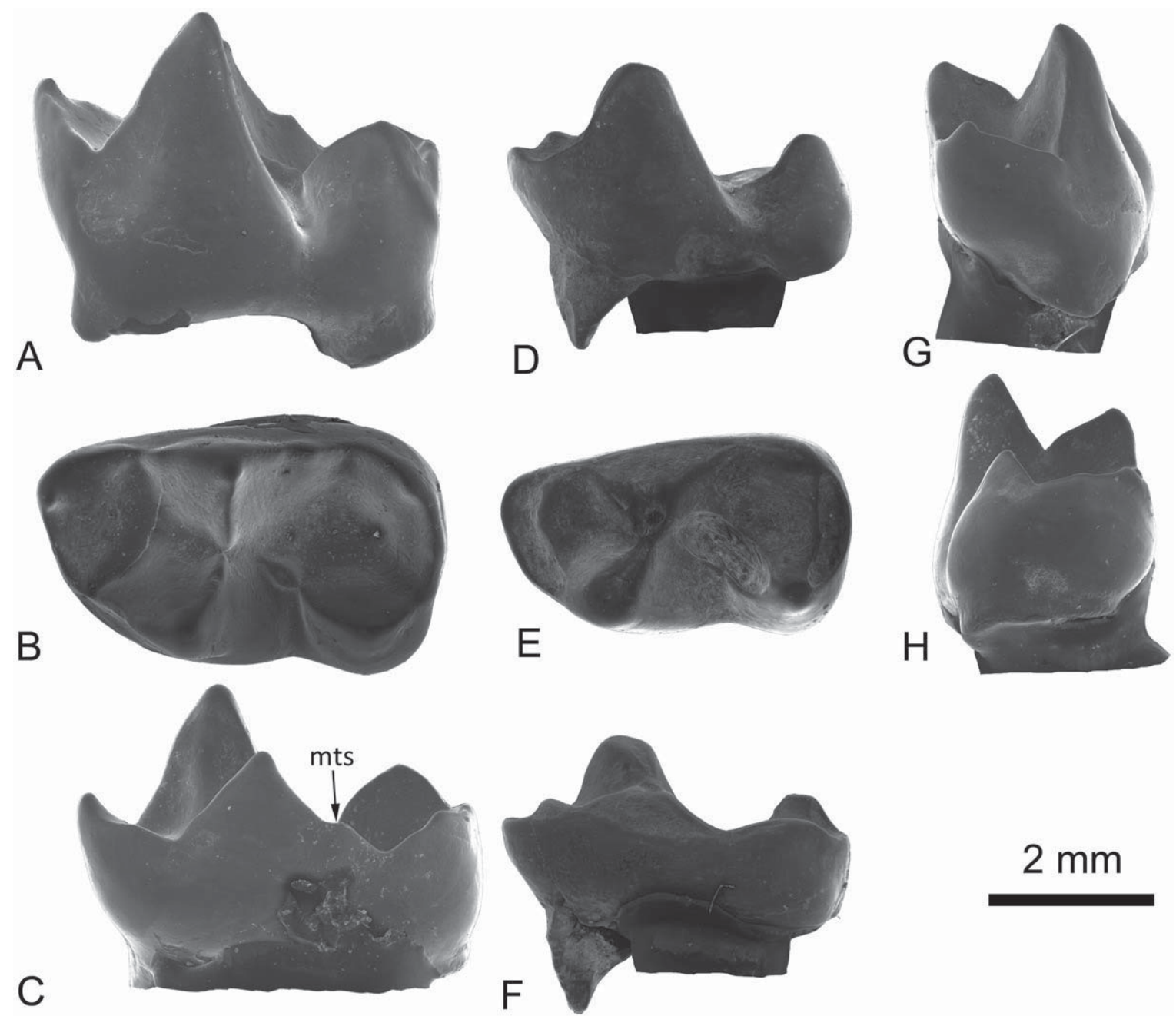

Figure 8. Sororodon tresvauxae gen. et sp. nov. A-C, MNHN.F.CEB 521 (holotype), right m1: A, labial view; B, occlusal view; C, lingual view. D-F, MNHN.F.Av4561, left $\mathrm{m} 2$ : D, labial view; E, occlusal view; F, lingual view. G, H, MNHN.F.CEB 521 (holotype), right m1: G, mesial view; H, distal view. Reversed views: A, B, F-H. Abbreviation: mts, metastylid.

on the mesiolabial facet of the paraconid on several specimens; the other specimens (Fig. 8A) do not have a precingulid.

The $\mathrm{m} 2$ is slightly smaller (Table 6) than the $\mathrm{m} 1$, but the two molars are similar in morphology. The paraconid is less mesially located and the talonid is slightly longer relatively to the trigonid on $\mathrm{m} 2$ than on $\mathrm{m} 1$ (Table 7). These differences between the $\mathrm{m} 1$ and $\mathrm{m} 2$ are also observed in the Lutetian paroxyclaenine
Kopidodon. It is, however, hard to distinguish between the two loci because the two $\mathrm{m} 2 \mathrm{~s}$ of the present sample are worn (especially the metaconid, hypoconulid and cristid obliqua), so our determination of the $\mathrm{m} 2 \mathrm{~s}$ should be regarded as uncertain. Moreover, some of the $\mathrm{m} 1 \mathrm{~s}$ are close in size to the $\mathrm{m} 2 \mathrm{~s}$ (Fig. 4), but their morphology better agrees with that of an $\mathrm{m} 1$ than an $\mathrm{m} 2$ (this is notably the case for MNHN.F.CEB525 and MNHN.F.Levé.Condé.924). 
Variability. The specimens of paroxyclaenines discovered at Mutigny, Avenay and Condé-en-Brie display less variability than those of other merialines from the same localities. However, this could be due to the poor sample size (only 11 specimens). Only the cuspulation of the entocristid and postcristid and the presence of an accessory cusp on the postparacristid vary within the sample.

Comparison. The fossils of the present taxon are only slightly smaller, but distinctly narrower, than those referred to Fratrodon tresvauxi (Fig. 4), and the two species are recorded in the same localities. These two taxa share moderately high-crowned molars, cuspulation of the entocristid and postcristid, the presence of a metastylid, a high entocristid that lingually encloses the talonid basin, a small difference in height between the trigonid and talonid, the shallow depth of the notches on the trigonid, the wide talonid, and the small size of the lingually located paraconid.

The two samples of isolated teeth differ in the less appressed apexes of the paraconid and metaconid: the paraconid is clearly more mesially and less lingually located than in the merialine $F$. tresvauxi. As a result, the protoconid part of the paracristid is longer and mesiodistally oriented (it is transversely oriented in merialines); due to this morphology, the trigonid is more ' $V$ '-shaped than in F. tresvauxi. Even if the morphology of the talonid recalls merialines, the wider separation of the paraconid and metaconid apexes and the position of the paraconid allow referral of the lower molars to Paroxyclaeninae rather than Merialinae. The teeth from Mutigny, Avenay and Condé-en-Brie grouped within this second sample are more mesiodistally elongated (Table 4).

Consequently, Rich (1971) was correct to erect two distinct taxa from among the fossils from Avenay and Mutigny. He was also right to conclude that one taxon is morphologically close to the merialine Spaniella (cf. Paroxyclaenidae in Rich 1971, but Fratrodon tresvauxi in the present paper), and that the other taxon is close to the paroxyclaenine Paroxyclaenus (cf. Paroxyclaenus in Rich 1971, Sororodon tresvauxae in the present paper). We disagree, however, with Rich (1971) in regarding MNHN.F.Mu6385 and MNHN.F.Mu5947 as possible m1s (Rich 1971 considered these two teeth to be m2s).

It is important to note that several molars, such as MNHN.F.Av4561 (Fig. 8D-F), display peculiarly severe wear on the lingual side, as noticed by Tobien (1969) and Koenigswald (1983) in Kopidodon and Paroxyclaenus (see Discussion, below).

Among paroxyclaenines, only Kopidodon, Paravulpavoides, Pugiodens, Paroxyclaenus and Vulpavoides vanvaleni are represented by lower molars; however, the holotype and sole specimen of Pugiodens has been missing since the 1960 s and the lower dentition of $V$. vanvaleni consists only of the $\mathrm{m} 3$. The new taxon differs from Paravulpavoides and Paroxyclaenus by its more mesially located paraconid, less rounded but longer paracristid, and also (possibly) by a wider talonid relative to the trigonid (this feature has, however, to be quantified in the future for all paroxyclaenid species). The general morphology of the molars found at Mutigny, Avenay and Condé-en-Brie is more similar to that of Kopidodon, the oldest paroxyclaenid found prior to this work (Fig. 1), than to Paravulpavoides and Paroxyclaenus. It is noteworthy that the lower molars of all paroxyclaenines are morphologically very similar (see Koenigswald 1983).

The new taxon from Mutigny, Avenay and Condé-enBrie differs from Kopidodon in its smaller size $(35 \%$ when considering the length of the $\mathrm{m} 1$ ). It also differs in its less appressed paraconid and metaconid (the paraconid is more mesially located in the fossils from the Paris Basin than in Kopidodon), its longer paracristid and its wider talonid on molars, based on comparisons with the illustrations of Kopidodon (Koenigswald 1983, fig. 4).

Fossils of $S$. tresvauxae are less abundant than those of $F$. tresvauxi (11 vs 34 specimens). This poor abundance might explain the absence of paroxyclaenines in localities that yield very few paroxyclaenids (i.e. Pourcy, Grauves and Prémontré). However, the very similar morphology of the two subfamilies also suggests that they were ecologically close; therefore, they might have co-occurred and the presence of merialines could have influenced the presence of paroxyclaenines.

\section{Discussion}

\section{The cases of Euhookeria hopwoodi and \\ Kiinkerishella zaisanica}

Russell \& Godinot (1988) referred Euhookeria hopwoodi from the Priabonian (Upper Headon beds, Lignite beds) to Merialinae. This species, which is represented by a mandible bearing the canine, p1-p4 and $\mathrm{m} 3$ (NHMUK PV M26052; holotype), one isolated p1 (NHMUK PV M26054) and one isolated m1 (NHMUK PV M26053), is interesting because (1) it would be the last representative of Paroxyclaenidae, and (2) its reference to Merialinae implies a very large gap in the fossil record for this subfamily (i.e. the entire middle Eocene, 47.8-38 Myr) (Fig. 1). Russell \& Godinot (1988) considered, however, that the $\mathrm{m} 1$ should be referred to another taxon. 
In their preliminary results of their study on the pantolestans from the Zaysan Basin (Kazakstan; upper Eocene), Lucas \& Emry (2000) noted a close relationship between Euhookeria and Oboia argillaceous, which is considered to be a pantolestine (Lucas \& Emry 2004).

Harrison (2009) compared the fossils of Paravulpavoides - the youngest paroxyclaenine (Fig. 1) - to those of E. hopwoodi (including a new isolated lower molar, HZM 1.19050). He concluded that "the paroxyclaenid affinities of Euhookeria hopwoodi appear rather uncertain, but it is clearly not closely related to Paravulpavoides" (Harrison 2009, p. 34). He remarked that the $\mathrm{m} 1$ of $E$. hopwoodi possesses a small projecting precingulid (a feature absent from Paravulpavoides cooperi), a talonid that is not reduced and that bears three distinct cusps, a small but distinct hypoconulid, and a low crestiform entoconid. The development of the precingulid is also visible on $\mathrm{m} 3$ of the holotype, and thus seems to be characteristic of Euhookeria. The hypoconulid is well developed on $\mathrm{m} 3$; the entoconid is crestiform, as on the possible molars (e.g. HZM 1.19050 and NHMUK PV M26053) referred to Euhookeria.

The referral of Euhookeria to Merialinae is based mainly on the closely appressed paraconid and metaconid (Russell \& Godinot 1988). This feature clearly distinguishes Euhookeria from Dyspterninae (a subfamily of Pantolestidae), including the genera Dyspterna and Cryptopithecus. Euhookeria also shares with merialines the presence of a simple p4 (i.e. no metaconid) and the reduction of the entoconid on molars. However, this is also the case in Dyspterninae (Cray 1973; Heissig 1977; Russell \& Godinot 1988).

However, several features of Euhookeria are inconsistent with the morphology of merialine teeth:

1. The upper half of the canine is triangular with sharp antero-internal, internal and postero-external crests; this morphology is observed in the dyspternines Dyspterna and Cryptopithecus, but not in Spaniella (Merialinae); the morphology of the canine in the paroxyclaenine Kopidodon is also different from that of Euhookeria.

2. The premolars of Euhookeria display a mesiolingual groove; this groove is not present on the premolars of Merialus and Spaniella. The latter genus possesses very simplified premolars with respect to those of Merialus.

3. The precingulid is well developed in Euhookeria but is extremely reduced in Merialus, Fratrodon and Spaniella and is absent in Paraspaniella.

4. The entoconid is reduced/absent in Euhookeria as also occurs in merialines (except in Paraspaniella), but the hypoconid and entoconid of the latter are replaced by a cuspulation and therefore are not as distinguishable as in Euhookeria; in Merialus, the entoconid is poorly individualized and the hypoconulid is tiny.

5. The talonid basin is distinctly lingually opened on the $\mathrm{m} 3$ of Euhookeria whereas all merialine molars have a high entocristid that reaches the metaconid, enclosing the talonid basin.

6. The hypoconid is much higher than the entoconid and hypoconulid in Euhookeria; this is not the case in merialines, but this is the case in Dyspterninae.

Based on all of these differences, the closely appressed paraconid and metaconid appear to be of little importance. Moreover, the morphology of the teeth of Euhookeria (triangular canine, mesiolingual groove on premolars, precingulid on molars, lingually opened talonid basin, distinguishable hypoconid and entoconid, high hypoconid) fits better with that of Dyspterninae than Merialinae. It is worth noting that the paraconid is not well developed in Dyspterninae, but as noted by Russell \& Godinot (1988), it is generally more medially placed, which is not the case on the $\mathrm{m} 3$ of the holotype of Euhookeria, but is the case on the two isolated molars (NHMUK PV M26053 and HZM 1.19050) doubtfully referred to Euhookeria.

Consequently, it appears that Euhookeria should be included in Dyspterninae; its inclusion in Merialinae would imply numerous important modifications of the canine, premolars and molars that do not fit with the observed evolution of merialines during the Ypresian. This new attribution would solve the problem of the gap in the merialine fossil record and implies that merialines inhabited Europe only during the Ypresian.

Kiinkerishella zaisanica from the upper Eocene (Ergilian Asian Land Mammal Age) of the Zaysan Basin (Kazakhstan) was considered to be a condylarth (Gabuniya \& Biryukov 1978) or a paroxyclaenid close to Paroxyclaenus (Russell \& Godinot 1988; Lucas \& Emry 2000), but was referred to Dyspterninae by Dashzeveg \& Russell (1992). The recent study of Lucas \& Emry (2004) concluded that Kiinkerishella is morphologically close to Gobiopithecus and Dyspterna and should be included within Dyspterninae.

This species was the sole potential paroxyclaenid known from outside Europe. Its reference to pantolestan dyspternines thus implies that paroxyclaenids were endemic to Europe. Moreover, because of the dyspternid affinities of Euhookeria and Kiinkerishella, as discussed above, it appears that paroxyclaenids went extinct before the late Eocene.

\section{Principal component analysis}

We performed a PCA on all of the complete lower molars in order to discriminate the four new 

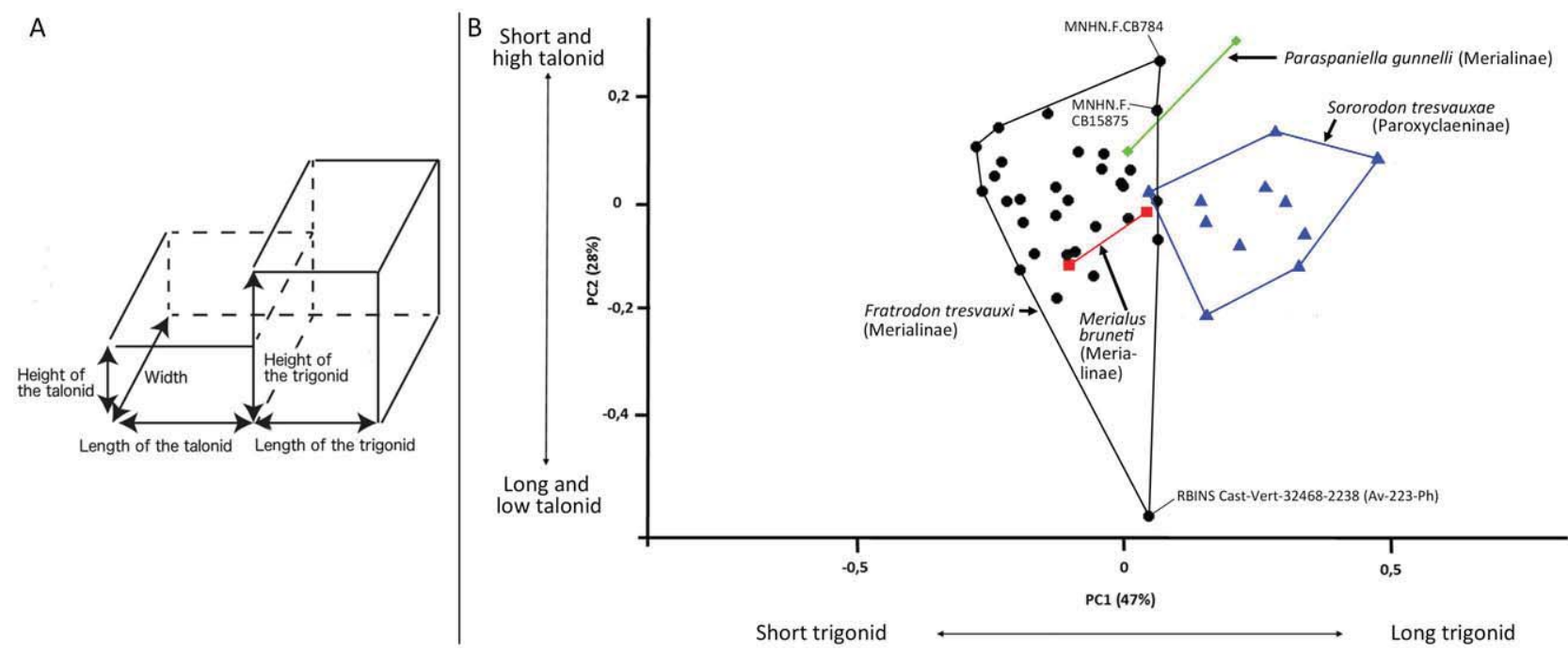

Figure 9. Principal component analysis (PCA) on all the complete lower molars $(n=46)$. A, illustration of the five measurements used for the PCA. B, biplot of the first two components of the PCA. Circles: Fratrodon tresvauxi; diamonds: Paraspaniella gunnelli; squares: Merialus bruneti; triangles: Sororodon tresvauxae.

paroxyclaenid species described herein. We used five measurements taken on the lower molars (Fig. 9A; Supplementary material, File 1). The first two principal components (PCs) represent $75 \%$ of shape variation $(\mathrm{PC} 1=47 \%$; $\mathrm{PC} 2=28 \%)$. PC1 accounts mainly for the variability in the length of the trigonid, while PC2 expresses variability in the length and height of the talonid. The distribution along $\mathrm{PC} 1$ and $\mathrm{PC} 2$ clearly separates the different subfamilies (Fig. 9B).

A clear separation is observed between Sororodon tresvauxae and Fratrodon tresvauxi along PC1 (Fig. 9B). The teeth of Sororodon tresvauxae are located on the positive side of $\mathrm{PC} 1$, meaning that their teeth are narrow with a long trigonid. Conversely, the teeth of Fratrodon tresvauxi are located on the negative side of PC1 (i.e. their teeth are broad with a short trigonid). The importance of trigonid morphology, notably the position of the paraconid and metaconid (i.e. closely appressed or not), for discriminating between merialines and paroxyclaenines was highlighted by Russell \& Godinot (1988) when they erected Merialinae. As the relative positions of the paraconid and metaconid directly influence the length of the trigonid, our PCA supports the importance of this character in paroxyclaenid systematics.

The other two species, Paraspaniella gunnelli and Merialus bruneti, occur within the morphospace created by specimens of Fratrodon tresvauxi (Fig. 9B). However, the former two taxa are represented by two specimens only (two m2s for $M$. bruneti and two $\mathrm{m} 1 \mathrm{~s}$ for P. gunnelli). Moreover, Paraspaniella gunnelli is located on the positive side of $\mathrm{PC} 2$ with a talonid that is high but short. By contrast, Merialus bruneti is on the negative side of PC2 with a talonid that is lower but longer. This agrees with the general evolution observed in Merialinae (see below).

A large disparity is observed for Fratrodon specimens along PC2 (Fig. 9B). This variability involves high variation in the height of the talonid. Some of the individuals have very high but short talonids, while the others have low but long talonids. Three specimens stand out from the other teeth: MNHN.F.CB784 (m2?), MNHN.F.CB15875 (m3) and RBINS Cast-Vert-32468-2238 (Av-223-Ph, m3) (Fig. 9B). MNHN.F.CB784 differs from other $\mathrm{m} 2 \mathrm{~s}$ in having a very high trigonid, being similar to $\mathrm{m} 1 \mathrm{~s}$ in this structure, but the other measurements are similar to those of m2s. RBINS Cast-Vert-32468-2238 (Av-223$\mathrm{Ph}$ ) differs from other $\mathrm{m} 3 \mathrm{~s}$ by its very small width and trigonid and talonid heights; the tooth seems to be vestigial when compared to other $\mathrm{m} 3 \mathrm{~s}$. MNHN.F.CB15875 differs from other $\mathrm{m} 3 \mathrm{~s}$ in the shortness of the talonid; however, the separation between the talonid and trigonid is not marked clearly in this specimen, which may have influenced the measurement of talonid length. Consequently, we think that the important variability in the Fratrodon teeth, which may be due to reduction of the functional importance of the $\mathrm{m} 2$ and $\mathrm{m} 3$ relative to the $\mathrm{m} 1$, could explain this distribution (see below).

Specimens of Sororodon cluster in the centre of PC2 (Fig. 9B), which suggests reduced variation of the shape and size of the talonid. Conversely, tooth variation in Sororodon takes place at the level of the trigonid (i.e. along PC1). 


\section{General evolution of paroxyclaenids}

The exclusion of Euhookeria and Kiinkerishella from Paroxyclaenidae and the description of four new species leaves 13 valid species within the family ranging from the Ypresian to Bartonian (MP7 to MP16) (Fig. 1). The oldest fossils that can be referred to Paroxyclaenidae lived in the early Ypresian in the south of France (Palette; MP7) and the Paris Basin (Pourcy; MP7, PE III biozone sensu Hooker 1996, 1998). They both belong to Merialinae.

As indicated above, the Pourcy fauna is probably aged between 56-55 Myr and that of Palette is considered close to $55 \mathrm{Myr}$ (Table 1). It is noteworthy that paroxyclaenids are unknown from Dormaal $(\sim 56$ Myr) although this fossiliferous locality provides numerous teeth that are similar in size to those of the oldest paroxyclaenids (i.e. Merialus). Consequently, paroxyclaenids seem to have appeared in Europe during the early Ypresian, shortly (500,000-1,000,000 years) after the Paleocene-Eocene Thermal Maximum (PETM).

As mentioned above, merialines (Merialus bruneti and $M$. martinae) are the earliest paroxyclaenids recorded in Europe. Paroxyclaenines (represented by Sororodon tresvauxae) make their first appearance later at Mutigny (between 54-52 Myr). This corroborates the recent hypothesis of Hooker (2015) that the Mammal Dispersal Event (MDE; Fig. 1), which resulted in a renewal of the European mammal fauna around the PETM event, can be separated into at least two phases.

The sudden appearance of paroxyclaenines is intriguing because $S$. tresvauxae displays a trigonid on its lower molars that is completely different from that of merialines: the trigonid is not as compressed mesiodistally, the paraconid and metaconid are not closely appressed, the paraconid is more mesially located and individualized, and the protoconid part of the paracristid is longer and mesiodistally oriented (whereas it is transversely oriented in merialines). This distinction is supported by our PCA. Consequently, the molars of paroxyclaenines are clearly different from those of merialines. The morphology of the talonid (hypoconulid and entoconid reduced, cuspulation of the entocristid) and the wear facets are, however, generally similar. Paroxyclaenines can be distinguished from merialines also by the molarized morphology of the p4 (Russell \& Godinot 1988). Unfortunately, the $\mathrm{p} 4 \mathrm{~s}$ of the paroxyclaenids from Mutigny, Condé-en-Brie and Avenay are unknown; this prevents reconstructing the evolution of this tooth. This aspect of the dentition of paroxyclaenines indicates that they potentially separated from merialines a long time before their first record (at Mutigny) and that they might have lived in a presently unexplored province of Europe during the early Ypresian. As a consequence, paroxyclaenines may be found in localities close to the MP7 reference level.

The presence of two distinct subfamilies early in paroxyclaenid history, as well as the rapid and wide distribution of its earliest representatives (i.e. merialines in the Paris Basin and southern France), may imply that paroxyclaenids originated during the Paleocene. The presence of two distinct morphotypes among the earliest paroxyclaenids and the difficulty of deriving a paroxyclaenine from a merialine indicate that the two subfamilies may have separated well before their appearance in the fossil record. An origination in the Paleocene (probably rapidly) followed by diversification in the late Paleocene thus seems reasonable.

It is important to remark that the paroxyclaenids are very rare in Palette and Pourcy: one mandible has been found in Palette and three isolated teeth at Pourcy. Surprisingly, the samples from Mutigny, Avenay and Condé-en-Brie, which are larger than those from Pourcy and Palette, show that merialines and paroxyclaenines are both recorded in the three localities. Because paroxyclaenines are less abundant than merialines, one can imagine that the absence of paroxyclaenines in Pourcy and Palette could only be due to sampling bias: paroxyclaenines are indeed only present in the fossil record in localities where merialines are abundant. This reasoning could be applied to the case of Prémontré. However, one might also hypothesize that because the two subfamilies were ecologically very close, the presence of merialines could have influenced the presence/absence of paroxyclaenines; consequently, merialines may have been genuinely absent from localities such as Pourcy, Palette and Prémontré.

The presence of more than one paroxyclaenid species in a locality is very rare: the only other locality that records two paroxyclaenids is Geiseltal obere Mittelkohle (Germany, Lutetian; MP13), where Pugiodens and Vulpavoides germanica were found. However, these two taxa are close in size and belong to Paroxyclaeninae (Fig. 1) - Van Valen (1965) even synonymized these two taxa. The merialine species in the Paris Basin localities is slightly heavier than the paroxyclaenine one (1.5 vs $1 \mathrm{~kg}$ ) (Supplementary material, File 2). This difference may suggest that they belonged to two distinct ecological guilds. However, this size difference does not seem significant enough to explain the presence of two very similar mammals in the same localities.

Merialines disappear rapidly from Europe: the last occurrence of this subfamily is the very large Spaniella from the late Ypresian of northern Spain (Barranc de 
Forals; MP10) and Paraspaniella from the late Ypresian of the Paris Basin (Prémontré and Grauves; MP10). Spaniella is the largest paroxyclaenid ever found (reaching $3.7 \mathrm{~kg}$ ) (Fig. 1; Supplementary material, File 2).

As observed for merialines, paroxyclaenines reached maximal body mass around the Ypresian-Lutetian transition (Fig. 1). Kopidodon from the Messel pit (MP11) weighed $2.8-3.0 \mathrm{~kg}$ based on the dentition $(3-5 \mathrm{~kg}$ based on postcranial elements) (Supplementary material, File 2).

In contast to the merialines, paroxyclaenines diversified during the Lutetian. This diversity is concomitant with the first intra-Eocene mammal turnover evidenced by Franzen (2003) (Fig. 1). At least four species are known in localities close to the MP13 reference level: Vulpavoides germanica, Pugiodens mirus, Paroxyclaenus lemuroides and Vulpavoides vanvaleni. The two taxa from Geiseltal obere Mittelkohle (MP13), V. germanica and Pugiodens, are very close in size, while Paroxyclaenus (from Mémerlin and Cuzal, France) and $V$. vanvaleni (from Bouxwiller, France) are smaller than the former and have sizes that recall those of the taxa from Mutigny, Avenay and Condé-en-Brie; these differences in size support the specific distinctions and probably result from differences in ecology.

As mentioned above, Van Valen (1965) synonymized Vulpavoides germanica and Pugiodens. Russell \& Godinot (1988), following Tobien (1969), rejected this synonymy, noting the difference in the relative size of the molars. The unreduced $\mathrm{m} 3$ of Pugiodens (see below), as logically noted by Russell \& Godinot (1988), does not fit with the reduced M3 seen in Vulpavoides germanica (and other paroxyclaenines). Moreover, based on the measurements provided by Matthes (1952), its lower molars are more square-shaped than those of the other paroxyclaenines. Therefore, we conserve the separation of $V$. germanica and Pugiodens. Consequently, Pugiodens appears to be unique among paroxyclaenines, which implies the existence of several different morphological 'subgroups' among paroxyclaenines during the Lutetian.

The important diversity observed in localities close to the MP13 reference level (Geiseltal obere Mittelkohle, Bouxwiller, Cuzal) is the last record of diversity among paroxyclaenids. Indeed, only one taxon - Vulpavoides simplicidens - is recorded in Egerkingen (Switzerland, Lutetian, MP14; the exact locality $-\alpha, \beta$ or $\gamma$ ? - is unknown). This taxon is morphologically close to $V$. germanica from Geiseltal obere Mittelkohle and V. simplicidens from Bouxwiller (Van Valen 1965; Russell \& Godinot 1988).
The last representative of the paroxyclaenids is Paravulpavoides cooperi from Creechbarrow (England; Bartonian, MP16) (Hooker 1986; Harrison 2009) (Fig. 1). This species corresponds to a new genus as discussed recently by Harrison (2009) and Harrison et al. (2012). This taxon is among the smallest paroxyclaenids ever recorded $(\sim 1 \mathrm{~kg})$ (Supplementary material, File 2 ). This taxon is original among Paroxyclaenidae in possessing an unreduced m3; this feature recalls Pugiodens.

The disappearance of paroxyclaenids is related to a profound modification of European mammal faunas. According to Franzen (2003), this modification, which he named the second intra-Eocene faunal turnover, occurred mainly at the Bartonian-Priabonian boundary, between the MP16 and MP17 (Fig. 1). This turnover led to a considerable replacement of taxa, particularly among palaeotheres and artiodactyls. On one hand, several large and primitive species of Palaeotherium (Perissodactyla) disappeared. On the other, Palaeotherium species of modern aspect, with molarized premolars and cheek teeth that exemplified the development of hypsodonty, appeared suddenly (Legendre et al. 1991; Franzen 2003). At the same time, lophiodonts, once abundant in Europe, vanished completely. Among Artiodactyla, Legendre et al. (1991) noted the acquisition of fusion between the cuboid and navicular in several lineages around the MP16 and MP17 boundary. Concerning 'insectivorous' mammals, the disappearances of Adapisoricidae (MP16) and Pantolestidae (MP17) (Legendre et al. 1991) happened at almost the same time as that of Paroxyclaenidae. All of these modifications to the mammal fauna likely resulted from climatic changes to increasing aridity and seasonality in European ecosystems (Franzen 2003; Mosbrugger et al. 2005).

\section{Ecology of paroxyclaenids and the evolution of body mass}

The skeleton of Kopidodon is well known thanks to the discovery of several almost-complete specimens in the Messel pit. These fossils provided crucial elements for understanding the ecology of paroxyclaenids. The skull of Kopidodon is rather short, with a broad muzzle and distinct sagittal and nuchal crests. The skeleton is robust: limb bones are stout and the humerus bears prominent deltopectoral and supinator crests. The mobile elbow joint allowed substantial supination of the forearm and the ankle was very flexible. The feet were plantigrade, with divergent first digits, and the clawbearing terminal phalanges were short, deep and laterally compressed (Koenigswald 1983; Rose 2006; Koenigswald et al. 2018). The long caudal series and the outline of soft tissues preserved in one of the 
Messel skeletons (Specimen 8; Clemens \& Koenigswald 1993) suggest that Kopidodon had a long, bushy tail. All of the postcranial features showed by the specimens from Messel indicate that Kopidodon was an arboreal mammal.

Specimen 8 of Kopidodon stands out because of the material contained within its stomach or intestinal tract. This material corresponds to unidentifiable seeds and fruit tissue; the remains of leaves are rare. As a result, Clemens \& Koenigswald (1993) concluded that Kopidodon was either an omnivore or a herbivore. This hypothesis agrees with the robust morphology of the teeth and the peculiar pattern of attrition seen on the teeth (Koenigswald 1983; see below). As noted by Teilhard de Chardin (1922), enlarged canines were present in Paroxyclaenus; the upper ones are particularly massive and straight. Harrison (2009) argued that the canines might have been used to pluck fruit from branches; he remarked that the dentition of fruit bats (Megachiroptera, such as Pteropus) is similar to that of Paroxyclaenus in having large canines and in the weak, flattened and widely spaced cheek teeth.

Numerous elements discussed above are unknown for the majority of paroxyclaenids. Only $P$. lemuroides, $K$. macrognathus, and $V$. germanica are represented by fragmentary cranial elements; these fossils are very similar (i.e. morphology of the canines, short rostrum, position of the infraorbital foramina, and distinct sagittal and nuchal crests). Unfortunately, only Kopidodon is represented by postcranial elements.

Based on these similarities, and because the dental elements of the paroxyclaenids discovered until now do not show important modifications to their morphology through time - the dentition of the earliest representatives already displays the typical features of the family - one can hypothesize that the diet of paroxyclaenids was maintained during the Eocene. The same can be hypothesized for locomotion. However, it is worth remembering that no postcranial material is known for paroxyclaenids other than Kopidodon. Because Kopidodon is one of the largest paroxyclaenids known (Supplementary material, File 2), its ecology (i.e. locomotion and diet) could have been very different from that of other paroxyclaenids and Kopidodon might have occupied a different ecological niche to other paroxyclaenids.

What about the evolution of body mass? The estimated body masses are given in the Supplementary material, File 2. Previously, Clemens \& Koenigswald (1993) estimated the body mass of Kopidodon based on measurements taken from postcranial elements (Supplementary material, File 2) and used the BODYMASS program designed by Gingerich (1990).
The estimated body masses that we found using the method of Legendre (1986) are all above $500 \mathrm{~g}$, except for Merialus bruneti (355 g), when using the parameters established for all the mammals (Supplementary material, File 2). The values found when using the parameters defined for all mammals range from $355 \mathrm{~g}$ to $2.5 \mathrm{~kg}$; those found when using the parameters set for large mammals range from $688 \mathrm{~g}$ to $3.6 \mathrm{~kg}$; and those found when using the parameters defined for herbivores are clearly the highest ones, ranging from $835 \mathrm{~g}$ to $5.1 \mathrm{~kg}$. The values found by Clemens \& Koenigswald (1993) range from 3 to $5.4 \mathrm{~kg}$ for Kopidodon and are thus closer to the latter estimated values.

As discussed by Legendre (1986) and Gingerich (1989), $500 \mathrm{~g}$ represents a break point (or threshold) in the distribution of mammal size. Gingerich (1989) noted that it corresponds to 'Kay's threshold' in the distribution of primate body mass: smaller primates derive their protein primarily from insects, while the source of protein is primarily leaves in larger primates.

Therefore, the diet reconstructed for Kopidodon (i.e. predominance of vegetable material) agrees with its body mass as reconstructed based on the methods of Legendre (1986) and Gingerich (1990) (i.e. above $500 \mathrm{~g}$ ). Moreover, because all species used here have a body weight that is above 'Kay's threshold' (except in $M$. bruneti for one of the three parameters; see above), we believe that all paroxyclaenids were frugivores/granivores (or omnivores).

The evolution of body mass of the paroxyclaenids is interesting to analyse (Fig. 1). Merialus bruneti from Pourcy (MP7) is the smallest (average body mass around $626 \mathrm{~g}$ ). The second oldest paroxyclaenid, Merialus martinae from Palette, already weighed around $1.4 \mathrm{~kg}$ (average body mass). Fratrodon tresvauxi weighed only $1.5 \mathrm{~kg}$, while Paraspaniella gunnelli is slightly lighter than $F$. tresvauxi, indicating a small decrease in the body size among the species recorded in the Paris Basin. Therefore, these new species do not indicate an important increase in merialine body weight during the Ypresian. However, Spaniella is considerably larger than Paraspaniella, and a similar difference in body mass (i.e. Spanish mammals heavier than those from the Paris Basin) has been noted among mesonychids (Solé et al. 2017). To conclude, there is no clear trend for body mass evolution among merialines.

Concerning paroxyclaenines, the oldest taxon Sororodon tresvauxae - is one of the smallest representatives of this subfamily (Fig. 1; Supplementary material, File 2); but two Lutetian taxa are close in weight to $S$. tresvauxae. Kopidodon is distinctly heavier than $S$. tresvauxae (Fig. 1; Supplementary material, File 2). However, the taxa that are younger than Kopidodon 
evolved smaller body mass (Fig. 1; Supplementary material, File 2). The weight range of paroxyclaenines, especially during MP13, is quite high (Fig. 1; Supplementary material, File 2). Moreover, it is interesting to note that the latest paroxyclaenine Paravulpavoides cooperi - is one of the smallest (Supplementary material, File 2). To conclude, as for the merialines, no trend can be clearly defined for paroxyclaenines.

As indicated above, the largest representatives of paroxyclaenids are found around the Ypresian/Lutetian boundary. This occurred in the two subfamilies: the merialine Spaniella from the latest Eocene (MP10) weighed around $3.7 \mathrm{~kg}$ (mean of the three estimated body masses; Supplementary material, File 2), while the paroxyclaenine Kopidodon from the earliest Lutetian (MP11) weighed around $2.8 \mathrm{~kg}$ (mean of the three estimated body masses; Supplementary material, File 2).

As previously mentioned, the body mass of Kopidodon is very different from those of other paroxyclaenids. Its ecology may thus have been very different. The same hypothesis can be envisaged for Spaniella because the other merialines have a small weight range $(0.6-1.5 \mathrm{~kg})$, even the penecontemporaneous Paraspaniella (1.2 kg). Consequently, Kopidodon and Spaniella might represent outliers among Paroxyclaenidae, probably because of an ecological shift.

The possibility for paroxyclaenids to develop large body mass around the Ypresian/Lutetian transition was probably triggered by the Early Eocene Climatic Optimum (EECO), which is one of the warmest periods of the past 70 myr (about 53-51 Myr; Zachos et al. 2008). A recent mean annual temperature (MAT) estimate for the mid-latitude marginal marine Belgian Basin during the EECO - based on otolith $\delta^{18} \mathrm{O}$ compositions of four non-migratory species belonging to the teleost families Congridae and Ophidiidae - equals $27.5^{\circ} \mathrm{C}$ (Vanhove et al. 2011). However, incremental analyses revealed a $\sim 9.5^{\circ} \mathrm{C}$ mean annual range of temperatures, similar to modern seasonality (Vanhove et al. 2011).

The warm climatic conditions during the EECO may have favoured the large body mass of several paroxyclaenids. Moreover, the increase in body mass through the Ypresian of Europe has recently been evidenced for the carnivorous mammals Proviverrinae (Solé et al. 2014, 2015) and Mesonychidae (Solé et al. 2018). However, these observations do not support a clear causal connection, and deeper studies (such as statistical analyses) still have to be done to affirm that the EECO is responsible for the body mass increase of some paroxyclaenids (among other mammals).
The Paris Basin experienced tropical conditions and reduced seasonal contrasts during the Ypresian, but transient cooling is recorded within this warm period during the deposition of the Sables de Cuise Formation, to which the fossiliferous locality of Grauves, where Paraspaniella is recorded, belongs (Huyghe et al. 2012, 2015). This may explain the smaller size of this merialine with respect to Fratrodon.

Two diversity maxima considering body weight can be defined: MP10 witnessed the largest variation range between two species (two merialines in this case; Fig. 1), while the variation recorded by the MP13 localities (four paroxyclaenines; Fig. 1) is comparatively smaller than in MP10 but larger than in the other periods. The body mass diversity seen in MP13 corresponds to a peak of species diversity among paroxyclaenids. However, the highest estimated body masses in MP13 are lower than those of the taxa from the Ypresian-Lutetian transition.

The Lutetian is characterized by long-term cooling that follows the EECO and continues until the Oligocene, except during the Middle Eocene Climatic Optimum (MECO; 40 Myr; Zachos et al. 2008). However, during the Lutetian, there were tropical climatic conditions in Europe with an increase in seasonality (especially in temperature) in Central Europe (Mosbrugger et al. (2005). Moreover, an important cooling - 'Lutetian cooling' ( 46-42 Myr) (Huyghe et al. 2015, fig. 7) - occurred before the MECO. This cooling period corresponds to the 'Intra-Eocene Mammal Turnover 1' ( MP12-13) proposed by Franzen (2003). After this turnover, paroxyclaenids are less diversified (Fig. 1). Following the MECO, the Bartonian is characterized by cooling that lasts until the Eocene-Oligocene boundary (Huyghe et al. 2012, 2015).

Although the Lutetian and Bartonian paroxyclaenids are smaller than the largest paroxyclaenids recorded around the Ypresian-Lutetian boundary (i.e. Spaniella and Kopidodon), they are more numerous than during the previous periods until the Intra-Eocene Mammal Turnover 1 (Fig. 1). It is presently hard to determine the reasons for such increases and decreases in diversity: numerous factors can be envisaged besides the cooling of global climate, such as competition, predation, etc.

The same remarks also apply to the presence of large paroxyclaenids around the Ypresian/Lutetian boundary, the decrease in paroxyclaenid body size during the Lutetian and their disappearance during the Bartonian: one can hypothesize that the continuous decrease in temperatures coupled to an increase of seasonality after the Ypresian/Lutetian boundary (see Mosbrugger et al. 2005), and thus a modification of the flora, might be responsible for both phenomena. However, the 
explanation is surely more complex. Indeed, most of the paroxyclaenines from the Lutetian and Bartonian have body masses close to those of the Ypresian merialines Sororodon, Paraspaniella and Merialus martinae, yet the temperatures and seasonality were different.

\section{Hypothesized faunal events in the Ypresian of Europe}

The period encompassing Pourcy-Palette (MP7 and PE III biozone sensu Hooker 1996, 1998) and Mutigny (MP8 + 9 and PE IV biozone sensu Hooker 1996, 1998) is characterized by numerous modifications to the mammal faunas: disappearances of Oxyaenodonta, Sinopaninae (Hyaenodonta), Coryphodon (Pantodonta) and Pachyaena (Mesonychidae); the first appearance of the 'miacid' Quercygale; dispersals from the Southern Province to the Northern Province of Proviverrinae (Hyaenodonta) and Lophiaspis (Perissodactyla); and dispersal from the Northern Province to the Southern Province of Plesiesthonyx (Tillodontia) (D. E. Savage et al. 1966; Lucas 1998; Laurent et al. 2010; Solé et al. 2013, 2014, 2018; Solé 2014). To these previous obsevations, we can now add the appearance of paroxyclaenines in the Paris Basin around this time.

Because this period of turnover is now well documented, we propose to name it the 'Intra-Ypresian Mammal Turnover' (Fig. 1) - however, this event must be extensively studied in future in order to be fully characterized. As mentioned above, the appearance of the paroxyclaenines may be due to dispersal from an unknown region into the Paris Basin during this period of faunal modification and interchanges.

The disappearance of the merialines at the end of the Ypresian is intriguing. One can note that this disappearance affected both the Paris Basin and the Iberian Peninsula. Badiola's (2004) analysis of the palaeoecological conditions of the Mazaterón and Zambrana mammal assemblages (Western Iberian Bioprovince) suggests that the change from a complex forest habitat to a more open environment that occurred in the late Eocene in several regions of Europe could have started earlier in the Western Iberian Bioprovince, influencing its faunal composition. Moreover, some dental features observed in perissodactyls and rodents could be interpreted as representing adaptations to chewing tough plants associated with the increasingly arid conditions in this region (Franzen 2003; Badiola 2004). Because paroxyclaenids were probably arboreal animals with an omnivorous or herbivorous diet (see below), one can therefore imagine that the reduction of forest habitat had a strong impact on the merialines. However, the data presented here corresponds to the Iberian Peninsula, not the Paris Basin. If the disappearance of Spaniella is understandable, based on palaeoenvironmental data, that of Paraspaniella is less clear.

The disappearance of the merialines contrasts with the radiations of the perissodactyls, artiodactyls, pantolestids and hyaenodonts around the MP10 reference level as evidenced by the fossils from Prémontré (D. E. Savage et al. 1966; Sudre \& Erfurt 1996; R. Smith 2001; Solé et al. 2014).

Conversely, Solé et al. (2018) recently reported the disappearance of mesonychids at the end of the Ypresian. Like the merialines, mesonychids were recorded from the whole of Europe; they are known from MP10 localities in the Paris Basin (Cuis), southern France (Mas de Piquet), and the north-eastern Iberian Peninsula (Corsà II, Castigaleu). The disappearances of merialines and mesonychids are thus concomitant. They are also partially similar in that these disappearances occurred in two European provinces: north-western and south-western Europe.

However, they are not entirely similar: the mesonychids all belonged to the same genus (Dissacus) despite their difference in size (Solé et al. 2018), while the MP10 merialines represent two distinct genera (Paraspaniella and Spaniella). Moreover, as discussed above, Spaniella is, like Kopidodon, clearly heavier than the other paroxyclaenids and thus may have occupied a particular ecological niche.

Nevertheless, these disappearances suggest that a poorly known faunal turnover took place at the end of the Ypresian in Europe, which we term the 'YpresianLutetian Mammal Turnover' (Fig. 1). It is potentially noteworthy that a transient cooling is recorded at the end of the Ypresian in the Paris Basin (Huyghe et al. 2015).

These disappearances occurred after the EECO. In North America, this warming is reflected in an increase in mammal diversity (Woodburne et al. 2009). Floras associated with the EECO in western Wyoming indicate a sharp increase in MAT to $23^{\circ} \mathrm{C}$, with wet, paratropical conditions at its beginning followed by a retreat to more seasonally dry conditions, but with the MAT still at megathermal levels $\left(c\right.$. $\left.20^{\circ} \mathrm{C}\right)$. Subsequent climatic deterioration, from 50-47 Myr, resulted in major diversity loss (Bridgerian Crash; Woodburne et al. 2009). No similar diversity loss has been found in European ecosystems, but the cases of the Merialinae and Mesonychidae point out the necessity to focus on this period in the future to determine whether or not a limited 'crash' occurred in Europe.

\section{Morphology of the premolars and molars}

All of the paroxyclaenids have molars that decrease in size from $\mathrm{M} 1 / \mathrm{m} 1$ to $\mathrm{M} 3 / \mathrm{m} 3$. The $\mathrm{M} 3$ and $\mathrm{m} 3$ are 
sometimes particularly reduced: the merialines Fratrodon tresvauxi and Spaniella carezi clearly show a reduction in size and alteration of the morphology of the $\mathrm{m} 3$ (the tooth is single-rooted in these taxa). However, this trend is not constant among paroxyclaenids. As mentioned above, Pugiodens is characterized by a poorly reduced $\mathrm{m} 2$ and $\mathrm{m} 3$ when compared to $\mathrm{m} 1$; however, the $\mathrm{m} 3$ is only represented by its two alveoli in the holotype and only specimen of this taxon. Unfortunately, study of Pugiodens is now impossible because the holotype has been missing since the 1960s (Van Valen 1965; Russell \& Godinot 1988). The weak reduction of the $\mathrm{m} 3$ is also found in Paravulpavoides it is one of its distinctive features, as noted by Harrison (2009).

As indicated above, a particularity of the paroxyclaenine dentition is the tendency to enlarge and molarize the third and fourth upper and lower premolars: all of these paroxyclaenids display a p4 that has a metaconid - unfortunately, the p4 of the newly described Sororodon tresvauxae is unknown. The p3 also tends to molarize: the p3 of Kopidodon is simpler than that of Pugiodens, Paroxyclaenus and Paravulpavoides and Kopidodon is older than these three taxa, which is why it has a less-molarized p3. Harrison (2009, pp. 32-33) summarized the implications of this dental tendency and, based on these data, hypothesized that paroxyclaenids were frugivores/granivores that ate hard fruits ('tough-skinned fruits' according to Koenigswald et al. 2018, p. 230): "The enlarged and variably molarised posterior premolars suggest a transfer of maximal crushing power forwards in the tooth row, which appears to support such a dietary regime. [...] The enlarged posterior premolars of the paroxyclaenines seem well adapted to produce a 'nutcracker' effect for a relatively hard dietary regime."

Russell \& Godinot (1988) noted that merialines differ from paroxyclaenines in the absence p3 and p4 molarization. The premolars of Spaniella (only the p2 and p3 have been discovered) are simpler than those of Merialus in the disappearance of the small tubercle present in the mesial part of the teeth of the latter. Merialines thus seem to have experienced a simplification of the premolars, a tendency that is opposite to that of paroxyclaenines. Moreover, these differences indicate that Spaniella may have had a very different ecology from Merialus.

Merialines are characterized by a closely appressed paraconid and metaconid. As mentioned above, the first merialines already show a very close paraconid and metaconid. However, this tendency increases through time: the paraconid is closer to and less separated from the metaconid in Spaniella and Paraspaniella than in
Merialus and Fratrodon. The paroxyclaenines also show this tendency; as mentioned above, the protoconid part of the paracristid is more mesially elongated and the paraconid is mesially located and less lingually located in Sororodon tresvauxae than in the youngest paroxyclaenines (Fig. 10). The protocristid and paracristid are also less acute and the notches on these crests are not distinguishable on the youngest paroxyclaenids. Another tendency visible on the lower molars is the reduction of the hypoconid and, to a lesser extent, the entoconid. A cuspulation of the postcristid and entocristid is visible in several paroxyclaenids (Fratrodon, Sororodon, Spaniella). This evolution of the talonid cusps occurred together with a shortening of the talonid combined with an increase of the height of the talonid in Merialinae this is supported by the PCA (see above). Finally, the precingulid also tends to get reduced over time in Paroxyclaenidae.

Concerning the upper molars, paroxyclaenines and merialines clearly differ due to a squarer morphology (in occlusal view) in Merialinae, while paroxyclaenines have more transversely elongated molars over time (Fig. 10; Table 3); however, this transverse elongation is less marked in Kopidodon than in younger paroxyclaenines such as Paroxyclaenus, Vulpavoides and Paravulpavoides. As on the lower molars, there is a decrease in the individualization of the structures of the upper molars, both in Merialinae and Paroxyclaeninae. This concerns the reduction of the paraconule and metaconule visible in the Ypresian, Lutetian and Bartonian paroxyclaenids, though the metaconule is actually individualized and very bulbous in Fratrodon. On the upper molars, one can observe a reduction of the metastylar and parastylar area, and more generally of the labial shelf (Fig. 10). Therefore, the upper molars have lost the triangular pattern that characterized the tribosphenic molar. This highlights the decreasing importance of the paraconid through time.

The transverse elongation of the upper molars is probably related to a peculiar feature of paroxyclaenines: their unusual dental wear pattern. Indeed, when studying the abrasive wear in Kopidodon and Paroxyclaenus, Koenigswald (1983) noted that this wear develops notably on the lingual aspects of the lower molars; this affects particularly the paraconid, metaconid and entoconid (Fig. 10). This pattern results from heavy wear due to the presence of an atypical occlusion between the protocone and talonid: in addition to the normal position, in which the protocone occludes with the talonid basin, there is a second position, in which trigon basin and protocone overlap the talonid lingually (i.e. the entocristid and distal wall of the metaconid) (Koenigswald 1983). This second position is mechanically possible due to the long distance between the 


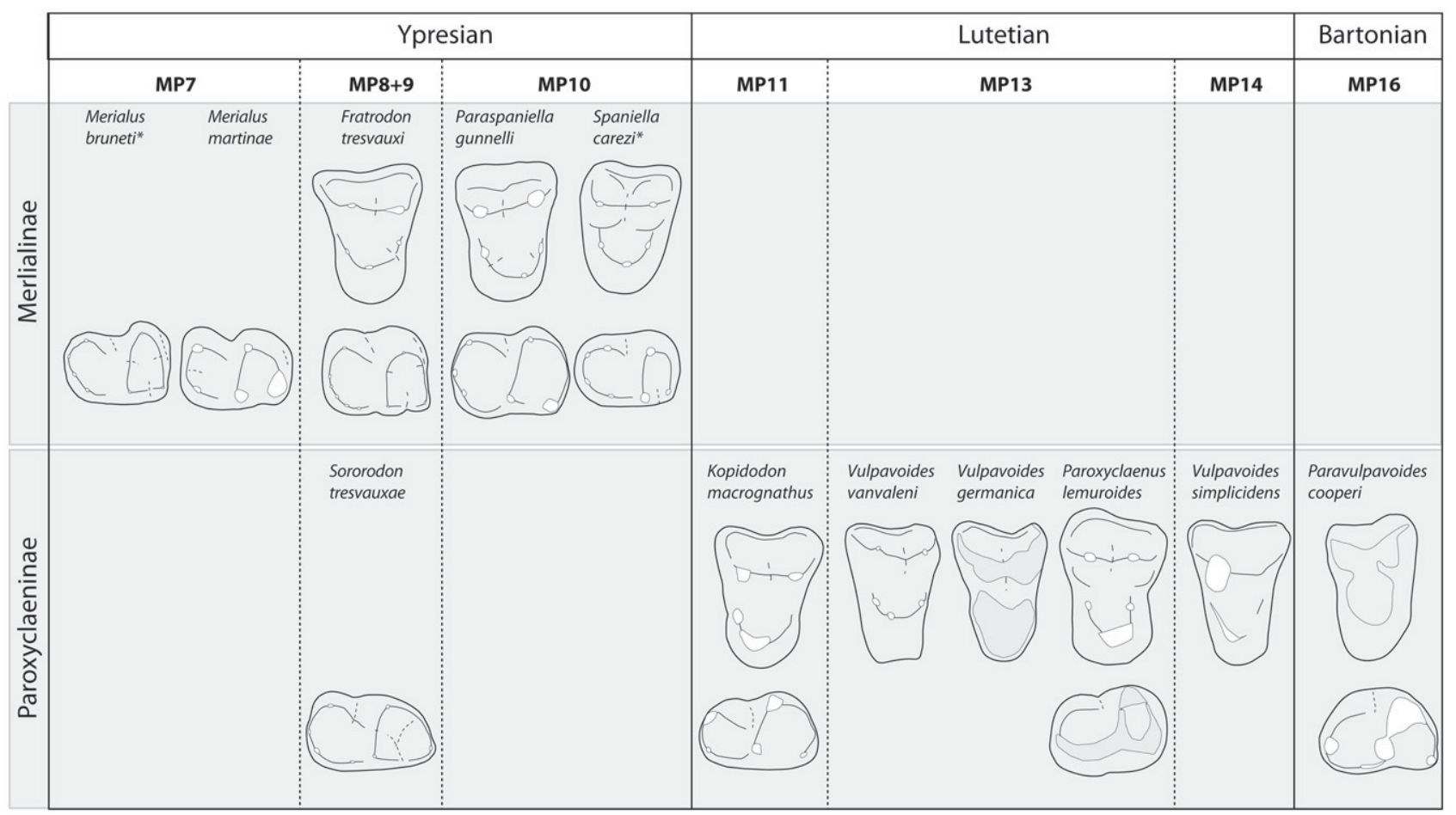

Figure 10. Comparisons of the left $\mathrm{M} 1$ and $\mathrm{m} 1$ of merialines and paroxyclaenines. Pugiodens mirus is not illustrated because we did not have access to suitable illustrations. We illustrated the $\mathrm{m} 2$ for Merialus bruneti and the $\mathrm{m} 2$ and M2 for Spaniella carezi. The teeth are not to scale. Merialus martinae after Russell \& Godinot (1988, fig. 1). Spaniella carezi after Crusafont-Pairo \& Russell (1967, figs 1, 2). Kopidodon macrognathus after Koenigswald (1983, fig. 4). Vulpavoides vanvaleni after Russell \& Godinot (1988, fig. 2). Vulpavoides germanica after Van Valen (1965, fig. 1). Paroxyclaenus lemuroides after Teilhard de Chardin (1922, fig. 38). Vulpavoides simplicidens after Van Valen (1965, fig. 2). Paravulpavoides cooperi after Harrison (2009, figs 1, 4).

protocone and the labial cusps (paracone and metacone) in the upper molars and the oblique labial wall of the hypoconid on the lower molars. The inclination of the hypoconid is notably marked in those paroxyclaenids that have a talonid as wide as the trigonid (i.e. F. tresvauxi, S. tresvauxae, M. martinae); it is less marked in younger paroxyclaenids probably because the talonid of the molars is less transversely elongated (Fig. 10). Importantly, the paroxyclaenine $S$. tresvauxae differs from Ypresian paroxyclaenids as it already displays wear facets that are typical of paroxyclaenines such as Kopidodon (Fig. 8E). Despite the inclination of the hypoconid, F. tresvauxi and M. martinae do not display the peculiar wear facets of paroxyclaenines. This unusual molar occlusion would allow for a hard diet (seeds? tough-skinned fruits?) and represents high nutritional specialization (Koenigswald 1983). This supports observations on the evolution of the premolars.

\section{Origin of Paroxyclaenidae}

The sudden appearance of paroxyclaenids in the European record combined with the existence of two distinct subfamilies since almost the first occurrences of this group raises questions about the origin of these mammals. Previous authors have considered the group to be creodonts (Teilhard de Chardin 1927), 'insectivores' (close to Procerberus; Van Valen 1965), mioclaenid 'condylarths' (Teilhard de Chardin 1927; Russell \& McKenna 1961) or arctocyonid 'condylarths' (Tobien 1969). Since the work of Russell \& Godinot (1988), Paroxyclaenidae has been included among pantolestans (Clemens \& Koenigswald 1993; McKenna \& Bell 1997; Rose 2006; see also Koenigswald et al. 2018).

Pantolestans probably originated in North America; the oldest pantolestan is Propalaeosinopa from the late Puercan (Cifelli et al. 1995; Rose 2006). McKenna \& Bell (1997) grouped the Pantolestidae, Pentacodontidae, Ptolemaiidae and Paroxyclaenidae among Pantolesta. However, recent studies concluded that Ptolemaiidae might be included within Afrotheria (Nishihara et al. 2005; Cote et al. 2007; Seiffert et al. 2007; Gunnell et al. 2010). Rose (2006) indicated that pantolestans have low-crowned molars with rounded cusps, upper molars with a narrow stylar shelf, lower molars with low trigonids and wide-basined talonids, and larger 


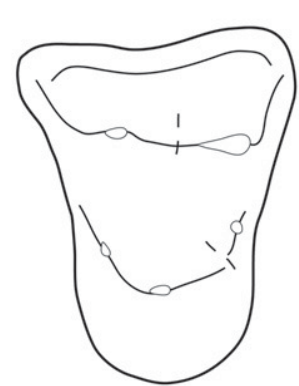

Fratrodon

tresvauxi

(Paroxyclaenidae)

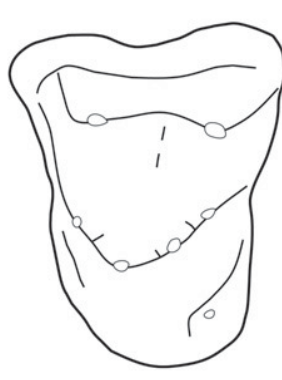

Eurolestes

dupuisi

(Pentacodontidae)

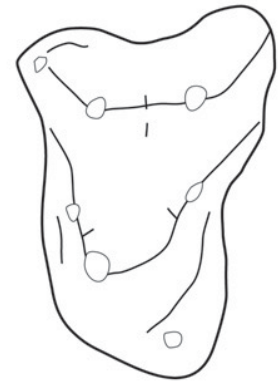

Bessoecetor

thomsoni

(Pantolestidae)

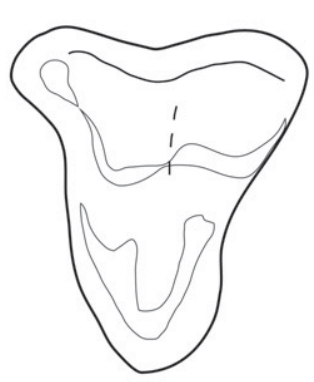

Procerberus

formicarum

(Cimolestidae)

Figure 11. Comparison of the M1 between the paroxyclaenid Fratrodon tresvauxi (RBINS Cast-Vert-32468-2240 [AV-1002-Ph]), the pentacodontid Eurolestes dupuisi (redrawn from De Bast \& Smith 2017, fig. 9), the pantolestid Bessoecetor thomsoni (redrawn from Simpson 1936, fig. 4) and the cimolestid Procerberus formicarum (redrawn from Lillegraven 1969, fig. 32). The teeth are not to scale.

premolars. The skulls of pantolestans known so far are moderately robust, with large canines, wide snouts and broad, well-developed occipital regions. The infraorbital foramen is large: this indicates that the maxillary nerve, which innervated a sensitive snout with tactile vibrissae, was large. Finally, the skeleton is robust with a long, well-developed tail. It is important, however, to remember that the skeletons of the paroxyclaenid Kopidodon and pantolestid Buxolestes show major differences (Clemens \& Koenigswald 1993).

The referral of paroxyclaenids to Pantolesta is difficult to refute, and the pantolestids and pentacodontids are the most similar mammals to paroxyclaenids presently known. In addition to the features listed by Rose (2006), these mammals share a separated paracone and metacone, a high protocone, and a large paraconule and metaconule on the upper molars; and a hypoconulid lower than the entoconid and hypoconid, and a small paraconid on the lower molars.

Pantolestids and pentacodontids differ from paroxyclaenids by the presence of wide pre- and postcingula (the latter often bearing a distinct hypocone cusp). These features are already visible in the earliest pantolestids such as Propalaeosinopa and Bessoecetor (Fig. 11). Pantolestids and pentacodontids also differ in the weak extension of the labial shelf. The upper molars discovered at Avenay and Condé-en-Brie show that the earliest paroxyclaenids have a developed labial shelf; moreover, there is no trace of pre- and postcingula on the upper molars.

Paroxyclaenids share with pentacodontids the relative size of the molars (i.e. they decrease in size posteriorly). Pantolestids clearly differ from pentacodontids and paroxyclaenids by possessing an $\mathrm{m} 1$ that is generally smaller than $\mathrm{m} 2$ and $\mathrm{m} 3$.
Because paroxyclaenids are endemic to Europe, it is essential to look at the fossil record of pantolestans in Europe. The first pentacodontid outside North America - Eurolestes dupuisi - was recently described from the (most likely) late Danian locality of Hainin (De Bast \& Smith 2017; Fig. 11). Like all pentacodontids, its $\mathrm{m} 3$ is smaller than its $\mathrm{m} 1$ and $\mathrm{m} 2$. It also shares with paroxyclaenids a preprotocrista that is shorter than the postprotocrista and a shallow and symmetrical ectoflexus. This species, like all pentacodontids, differs from the earliest paroxyclaenids by the presence of pre- and postcingula, a short labial shelf, the presence of an accessory cuspule between the protocone and the metaconule, a rounded molar outline, a less pronounced difference in height between the trigonid and talonid, a smaller and less lingually located paraconid, a bulbous entoconid and low entocristid, and a developed precingulid.

Consequently, evolution from Eurolestes to paroxyclaenids would necessitate an increase in paraconid height; lingual elongation of the paracristid; reduction of the entoconid; increase in entocristid height; reduction of the precingulid; expansion of the stylar shelf; reduction of the pre- and postcingula; and disappearance of the accessory cuspule between the protocone and metaconule. These transformations do not seem impossible because some are consequences of crushing adaptations (e.g. modifications of the entoconid and entocristid). Moreover, the time span between Eurolestes and the earliest paroxyclaenids covers the Selandian, Thanetian and beginning of the Ypresian (c. $6 \mathrm{Myr}$ ). However, the increase of the importance of the stylar shelf and paraconid (two structures that are related due to occlusion) is problematic and implies a phase of development of these structures (from Eurolestes to the earliest paroxyclaenids) before a regression (in the youngest 
paroxyclaenids). As noticed by Koenigswald (1983), transverse elongation seems to have been crucial for occlusion in paroxyclaenids; consequently, one can imagine that the importance of the paracristid and labial shelf (including the para- metastylar areas) might have increased transversely between Eurolestes and the earliest paroxyclaenids. This transformation does not seem improbable.

The oldest European pantolestid is Pagonomus dionysi from the Cernaysian fauna (Russell 1964) - the species Nosella europaea described by López-Martinez and Peláez-Campomanes (1999) has been recently considered a possible adapisoriculid (Jehle et al. 2012). This species differs from the earliest paroxyclaenids by the presence of a large hypocone, very reduced stylar shelf, reduced ectoflexus, reduced trigon basin, smaller paraconid, medially located paraconid and the presence of a precingulid. Because of these differences, it appears difficult to derive paroxyclaenids from $P$. dionysi. Moreover, unlike the pentacodontid Eurolestes, Pagonomus is first recorded in the Thanetian (MP6a) of Cernay-lès-Reims (see Hooker \& Russell 2012 for a discussion concerning the localities of Cernay and Berru).

Russell \& Godinot (1988) envisaged a relationship (that "merits reflection", p. 328) between Merialinae and Ptolemaiidae. This family is known only from Africa (Gunnell et al. 2010). It has been provisionally placed within Pantolesta (Bown \& Simons 1987; McKenna \& Bell 1997; Rose 2006), but recent studies indicate that these mammals might be closer to Afroinsectiphilia (especially Macroscelidea and Tubulidentata) and thus regarded as afrotherians (Nishihara et al. 2005; Cote et al. 2007; Seiffert et al. 2007; Miller et al. 2015). Paroxyclaenids appeared in Europe at approximately the same time as Hyaenodonta (i.e. around the Paleocene-Eocene boundary), a group that possibly originated in Africa (Solé et al. 2015; but see Borths et al. 2016 for a different opinion); hyaenodonts and paroxyclaenids are, for example, both recorded in Palette. The ptolemaiids are first recorded in the late Eocene, but this material has not yet been described (Gunnell et al. 2010). Ptolemaia lyonsi (from the early Oligocene Jebel Qatrani Formation, Quarry A) is therefore the oldest well-described ptolemaiid (Osborn 1908; Simons \& Gingerich 1974; Gunnell et al. 2010); a second species from the early Oligocene, $P$. grangeri, has been described by Bown \& Simons (1987). A second genus, Cleopatrodon (containing two species) is also known from the early Oligocene (Bown \& Simons 1987). A third genus, Kelba (one species) is known from the early and middle Miocene (R. J. G. Savage 1965; Cote et al. 2007).
As noted by Russell \& Godinot (1988), Ptolemaia shares with paroxyclaenids a large p3 and p4, and with paroxyclaenines the presence of a metaconid on $\mathrm{p} 4$. However, they also noted that the molars of ptolemaiids are much higher than those of paroxyclaenids. The two groups share the presence of a protocone on $\mathrm{P} 3$, which is shifted far posteriorly in ptolemaiids (Cote et al. 2007); the separation of the paracone and metacone; and the closely appressed metaconid and paraconid. Some of the typical features of ptolemaiids that are not found in paroxyclaenids are the large protocone and well-developed buccal cingulum, and the absence of preparacrista (Cote et al. 2007). Another difference is the weak development of the labial shelf and its asymmetry in Ptolemaiidae. The dental features of Ptolemaiidae are clearly different from the morphology of paroxyclaenids. Concerning the skull, Cote et al. (2007) listed, as characteristic features of the Ptolemaiidae, the anterior opening of the infraorbital canal above P3 and a retracted nasal aperture (seen in lateral view) with the premaxilla extending far ventrally relative to its dorsal margin. These two features also distinguish Ptolemaiidae from Paroxyclaenidae.

Crusafont-Pairo \& Russell (1967) rejected the similarity between the cimolestan Procerberus (Didelphodonta, Cimolestidae) and paroxyclaenids that was underlined by Van Valen (1965), primarily on the basis of the morphology of the labial shelf, which is not symmetrical in Paroxyclaenidae (Crusafont-Pairo \& Russell 1967 based their hypothesis on Spaniella, which was the earliest paroxyclaenid known at that time). The newly described fossils from the Paris Basin show that the oldest paroxyclaenids have a wide stylar shelf that is symmetrical in occlusal view. Moreover, these fossils recall the cimolestan Procerberus in the absence of a hypocone: as discussed above, the presence of this derived structure is typical of Pentacodontidae and Pantolestidae. Therefore, the earliest paroxyclaenids (both the merialines and paroxyclaenines) are closer in some features to the cimolestans such as Procerberus than to the pantolestans. The paroxyclaenids described in the present paper also share with some cimolestids a higher and more developed paraconid than in pantolestans, as well as the important difference in height between the trigonid and talonid. However, it is worth highlighting that these similarities concern a number of dental features, but not the whole dentition. Regarding this problem, it should be noted that the premolars of the paroxyclaenids and Procerberus are quite different.

Consequently, one can hypothesize that the similarities (e.g. narrow stylar shelf on upper molars, lower molars with low trigonids and wide basined talonids) between several paroxyclaenids and pantolestans may be due to convergence. To conclude, the hypothesis of Van 
Valen (1965) should not be entirely rejected and must be kept in mind when analysing the origin and evolution of paroxyclaenids.

\section{Conclusions}

Russell \& Godinot (1988) noted that they aimed to study the paroxyclaenids from the Ypresian of the Paris Basin based on material discovered since Rich's (1971) study, but this work was not concluded. However, they noted that both subfamilies (i.e. Paroxyclaeninae and Merialinae) were present in the Ypresian of the Paris Basin.

The present study describes four new paroxyclaenid species, all from the Ypresian. These new species considerably increase the diversity of paroxyclaenids from the Ypresian and their study confirms the suggestion of Russell \& Godinot (1988) that the radiation of paroxyclaenids (i.e. the split between merialines and paroxyclaenines) took place no later than the early Ypresian.

These species provide important information on the molar morphology in the earliest representatives of this group. The molar morphology described in the present paper is closer to that of cimolestids in several dental features, casting doubt on the hypothesis of a close relationship with pantolestans, as had been suggested since the 1970s, and leaves open the questions of paroxyclaenid relationships and origins.

\section{Acknowledgements}

We thank B. Marandat and S. Jiquel (Université de Montpellier) for access to the type of Merialus martinae. We also thank G. Billet, C. Sagne and V. Pernègre $(\mathrm{MNHN})$ for access to the fossils housed at the MNHN. We thank E. De Bast (RBINS) for the SEM pictures of UM/POY12 and P. Loubry (MHNN) for his help with the SEM pictures taken at the MNHN. Finally, we warmly thank Thomas Lehmann and one anonymous reviewer for their insightful reviews, which led to significant improvements in the manuscript. This research was financially supported by the Federal Science Policy Office of Belgium (Belspo Brain project BR/121/A3/PalEurAfrica).

\section{Supplementary material}

Supplementary material associated with this contribution can be accessed here: https://doi.org/10.1080/14772019. 2018.1551248 .

\section{References}

Aubry, M.-P., Thiry, M., Dupuis, C. \& Berggren, W. A. 2005. The Sparnacian deposits of the Paris Basin: a lithostratigraphic classification. Stratigraphy, 2, 65-100.

Badiola, A. 2004. Estudio Paleontológico del Yacimiento del Eoceno Superior de Zambrana (Á lava, Región VascoCantbrica). Tafonomía, Paleobiología de Mamíferos e Implicaciones Biocronológicos. Unpublished $\mathrm{PhD}$ thesis, Euskal Herriko Unibertsitatea/Universidad del País Vasco, Leioa, Spain, 417 pp.

Baylac, M. \& Friess, M. 2005. Fourier descriptors, Procrustes superimposition, and data dimensionality: an example of cranial shape analysis in modern human populations. Pp. 145-165 in D. E. Slice (ed.) Modern Morphometrics in Physical Anthropology. Kluwer Academic/Plenum Publishers, New York.

BiochroM'97. 1997. Synthèses et corrélations. Pp. 769-805 in J.-P. Aguilar, S. Legendre \& J. Michaux (eds) Actes du colloque international de biostratigraphie BiochroM'97. Mémoires et Travaux de l'EPHE 21, Montpellier. Ecole Pratique des Hautes Etudes, Institut de Montpellier.

Borths, M. R., Holroyd, P. A. \& Seiffert, E. R. 2016. Hyainailourine and teratodontine cranial material from the late Eocene of Egypt and the application of parsimony and Bayesian methods to the phylogeny and biogeography of Hyaenodonta (Placentalia, Mammalia). PeerJ, 4, e2639.

Bown, T. M. \& Simons, E. L. 1987. New Oligocene Ptolemaiidae (Mammalia:? Pantolesta) from the Jebel Qatrani Formation, Fayum Depression, Egypt. Journal of Vertebrate Paleontology, 7, 311-324.

Cavelier, C. 1987. Diachronisme des faciès et discontinuités dans le Paléogène. Exemple du Thanétien et de l'Yprésien en Ile-de-France. Essai de generalisations et corrélations dans les bassins anglais, beige et parisien. Pp. 244-270 in C. Cavelier \& J. Lorenz (eds) Aspects et Evolution Géologiques du Bassin Parisien, Bulletin d'Information des Geologues du Bassin de Paris, Memoire hors serie, 6.

Cifelli, R. L., Czaplewski, N. J. \& Rose, K. D. 1995. Additions to knowledge of Paleocene mammals from the North Horn Formation, central Utah. The Great Basin Naturalist, 55, 304-314.

Claude, J. 2013. Log-shape ratios, Procrustes superimposition, elliptic Fourier analysis: three worked examples in $R$. hystrix: Italian Journal of Mammalogy, 24, 94-102.

Clemens, W. A. \& Koenigswald, W. von. 1993. A new skeleton of Kopidodon macrognathus from the Middle Eocene of Messel and the relationships of paroxyclaenids and pantolestids based on postcranial evidence. Kaupia, 3, $57-73$.

Cote, S., Werdelin, L., Seiffert, E. R. \& Barry, J. C. 2007. Additional material of the enigmatic early Miocene mammal Kelba and its relationship to the order Ptolemaiida. Proceedings of the National Academy of Sciences of the United States of America, 104, 5510-5515.

Cray, P. E. 1973. Marsupialia, Insectivora, Primates, Creodonta and Carnivora from the Headon Beds (Upper Eocene) of southern England. Bulletin of the British Museum (Natural History) Geology, 23, 1-102.

Crusafont-Pairo, M. \& Russell, D. E. 1967. Un nouveau Paroxyclaenide de l'Eocène d'Espagne. Bulletin $d u$ 
Muséum National D’histoire Naturelle, Série 2, 39, $757-773$.

Dashzeveg, D. \& Russell, D. E. 1992. Extension of dyspternine Pantolestidae (Mammalia, Cimolesta) in the early Oligocene of Mongolia. Geobios, 25, 647-650.

De Bast, E. \& Smith, T. 2017. The oldest Cenozoic reference mammal fauna of Europe: implications of the early Palaeocene Hainin fauna (Belgium) in mammalian evolution and dispersals during the Palaeocene. Journal of Systematic Palaeontology, 15, 741-785.

Duprat M. 1997. Les faciès à mammifères (MP 6 à MP16) dans le Nord-Est du Bassin de Paris (France): argumentation du modèle tectono-sédimentaire des dépôts paléogènes. Pp. 315-336 in J.-P. Aguilar, S. Legendre \& J. Michaux (eds) Actes du colloque international de biostratigraphie BiochroM'97. Mémoires et Travaux de l'EPHE 21, Montpellier. Ecole Pratique des Hautes Etudes, Institut de Montpellier.

Escarguel, G. 1999. Les rongeurs de l'Eocène inférieur et moyen d'Europe Occidentale. Systématique, phylogénie, biochronologie et paléobiogéographie des niveaux-repères MP 7 à MP 14. Palaeovertebrata, 28, 89-351.

Fabre, A.-C., Cornette, R., Huyghe, K., Andrade, D. V. \& Herrel, A. 2014. Linear versus geometric morphometric approaches for the analysis of head shape dimorphism in lizards. Journal of Morphology, 275, 1016-1026.

Franzen, J. L. 2003. Mammalian faunal turnover in the Eocene of central Europe. Geological Society of America, Special Papers, 369, 455-461.

Gabuniya, L. K. \& Biryukov, N. D. 1978. O prisutstvii svoyebraznovo predstavitelya arktotsionoidey (Arctocyonoidea) v Paleogene Azii [On the presence of a peculiar representative of the arctocyonoids in the Paleogene of Asia]. Soobshcheniya Akademiia Nauk Gruzinskoi SSR, 92, 489-492. [In Russian.]

Gingerich, P. D. 1989. New earliest Wasatchian mammalian fauna from the Eocene of northwestern Wyoming: composition and diversity in a rarely sampled highfloodplain assemblage. Museum of Paleontology, Papers on Paleontology, 28, 1-97.

Gingerich, P. D. 1990. Prediction of body mass in mammalian species from the long bone lengths and diameters. Contributions from the Museum of Paleontology, 28, 79-92.

Gunnell, G. F., Gingerich P. D. \& Holroyd, P. A. 2010. Ptolemaiida. Pp. 83-87 in L. Werdelin \& W. J. Sanders (eds) Cenozoic Mammals of Africa. University of California Press, Berkeley.

Harrison, D. L. 2009. A new genus of paroxyclaenid (Mammalia: Condylarthra: Paroxyclaenidae: Paravulpavoides) from the upper middle Eocene of Creechbarrow, Dorset, S. England. Cainozoic Research, 6, $25-35$.

Harrison, D. L., Bates, P. J., Pearch, M., Michaels, C. \& Ward, D. J. 2012. New additions to the late middle Eocene mammal fauna of Creechbarrow, Dorset, southern England. Cainozoic Research, 9, 65-85.

Heissig, K. 1977. Neues Material von Cryptopithecus (Mammalia, Pantolestidae) a us dem Mittel oligozän von Mohren 13" in Mittelfranken. Mitteilungen der Bayerischen Staatssammlung für Paläontologie und Historische Geologie, 17, 213-225.
Hooker, J. J. 1986. Mammals from the Bartonian (middle/late Eocene) of the Hampshire Basin. Bulletin of the British Museum (Natural History) (Geology), 39, 191-478.

Hooker, J. J. 1996. Mammalian biostratigraphy across the Paleocene-Eocene boundary in the Paris, London and Belgian basins. Pp. 205-218 in R. W. Knox \& R. E. Dunay (eds) Correlation of the Early Paleogene in Northwest Europe. Geological Society of London, Special Publications, 101.

Hooker, J. J. 1998. Mammalian faunal change across the Paleocene-Eocene transition in Europe. Pp. 428-450 in M.-P. Aubry, S. G. Lucas \& W. A. Berggren (eds) Late Paleocene-Early Eocene Climatic and Biotic Events in the Marine and Terrestrial Records. Columbia University Press, New York.

Hooker, J. J. 2010. The mammal fauna of the early Eocene Blackheath formation of Abbey Wood, London. Monographs of the Palaeontographical Society, 165, $1-162$.

Hooker, J. J. 2015. A two-phase mammalian dispersal event across the Paleocene-Eocene transition. Newsletters on Stratigraphy, 48, 201-220.

Hooker J. J. \& Russell, D. E. 2012. Early Palaeogene Louisinidae (Macroscelidea, Mammalia), their relationships and north European diversity. Zoological Journal of the Linnean Society, 164, 856-936.

Huyghe, D., Lartaud, F., Emmanuel, L., Merle, D. \& Renard, M. 2015. Palaeogene climate evolution in the Paris Basin from oxygen stable isotope $\left(\delta^{18} \mathrm{O}\right)$ compositions of marine molluscs. Journal of the Geological Society, 172, 576-587.

Huyghe, D., Merle, D., Lartaud, F., Cheype, E. \& Emmanuel, L. 2012. Middle Lutetian climate in the Paris Basin: implications for a marine hotspot of paleobiodiversity. Facies, 58, 587-604.

Jehle, M., Godinot, M., Delsate, D., Phélizon, A. \& Pellouin, J.-L. 2012. A new late Paleocene micromammal fauna from Montchenot (Paris Basin). Preliminary results. Palaeobiodiversity and Palaeoenvironments, 92, 487-496.

Koenigswald, W. von. 1983. Skelettfunde von Kopidodon (Condylarthra, Mammalia) aus dem mitteleozänen Olschiefer von Messel bei Darmstadt. Neues Jahrbuch für Geologie und Paläontologie, Abhandlungen, 167, 1-39.

Koenigswald, W. von., Gunnell, G. F., Lehmann, T., Rose, K. \& Ruf, I. 2018. Four archaic yet highly specialized mammals. Pp. 223-233 in K. T. Smith, S. K. F. Schaal \& J. Habersetzer (eds) Messel: An Ancient Greenhouse Ecosystem. Schweitzerbart, Stuttgart.

Laurain, M., Barta, L., Bolin, C., Gruas-Cavagnetto, C., Louis, P. \& Thiry, M. 1983. Le sondage et la coupe du Mont-Bernon à Epernay (Marne). Etude sédimentologique et paléontologique du stratotype du Sparnacien et de la série éocène. Géologie de la France, 3, 235-254.

Laurent, Y., Adnet, S., Bourdon, E., Corbalan, D., Danilo, L., Duffaud, S., Fleury, G., Garcia, G., Godinot, M., Le Roux, G., Maisonnave, C., Métais, G., MourerChauviré, C., Presseq, B., Sigé, B. \& Solé, F. 2010. La Borie (Saint-Papoul, Aude): un gisement exceptionnel dans l'Éocène basal du Sud de la France. Bulletin de la Société d'Histoire Naturelle de Toulouse, 146, 89-103.

Lavocat, R. 1958. Condylarthra. Pp. 1-27 in J. Piveteau (ed.) Traité de Paleontologie, Tome Vl-2. Masson et Cie, Paris. 
Legendre, S. 1986. Analysis of mammalian communities from the late Eocene and Oligocene of southern France. Palaeovertebrata, 16, 191-212.

Legendre, S., Crochet, J.-Y., Godinot, M., Hartenberger, J.-L., Marandat, B., Remy, J. A., Sigé, B., Sudre, J. \& Vianey-Liaud, M. 1991. Evolution de la diversité des faunes de mammifères d'Europe occidentale au Paléogène (MP 11 à MP 30). Bulletin de la Société Géologique de France, 162, 867-874.

Lenz, O. K., Wilde, V., Mertz, D. F. \& Riegel, W. 2015. New palynology-based astronomical and revised ${ }^{40} \mathrm{Ar} /{ }^{39} \mathrm{Ar}$ ages for the Eocene maar lake of Messel (Germany). International Journal of Earth Sciences, 104, 873-889.

Lillegraven, J. A. 1969. Latest Cretaceous mammals of upper part of Edmonton Formation of Alberta, Canada, and review of marsupial-placental dichotomy in mammalian evolution. University of Kansas Paleontological Contributions, 50, 1-122.

López-Martínez, N. \& Peláez-Campomanes, P. 1999. New mammals from south-central Pyrenées (Tremp formation, Spain) and their bearing on late Paleocene marinecontinental correlations. Bulletin de la Société Géologique de France, 170, 681-696.

Louis, P. 1996. Recherches de mammifères paléogènes dans les départements de l'Aisne et de la Marne pendant la deuxième moitié du vingtième siècle. Palaeovertebrata, 25, 83-113.

Lucas, S. G. 1998. Fossil mammals and the Paleocene/Eocene series boundary in Europe, North America, and Asia. Pp. 451-500 in M.-P. Aubry, S. G. Lucas \& W. A. Berggren (eds) Late Paleocene-Early Eocene Climatic and Biotic Events in the Marine and Terrestrial Records. Columbia University Press, New York.

Lucas, S. G. \& Emry, R. J. 2000. Eocene pantolestids from the Zaysan Basin, Kazakstan. Journal of Vertebrate Paleontology, 20(3, supplement), 54A-55A.

Lucas, S. G. \& Emry, R. J. 2004. Eocene Pantolesta from the Zaysan Basin, Kazakstan. New Mexico Museum of Natural History and Science Bulletin, 26, 227-229.

Marandat, B., Crochet, J.-Y., Godinot, M., Hartenberger, J.-L., Legendre, S., Remy, J. A., Sigé, B., Sudre, J. \& Vianey-Liaud, M. 1993. Une nouvelle faune à mammifères d'âge Eocène moyen (Lutétien supérieur) dans les phosphorites du Quercy. Geobios, 26, 617-623.

Matthes, H. W. 1952. Die Creodontier aus der mitteleozänen Braunkohle des Geiseltales. Hallesches Jahrbuch für Mitteldeutsche Erdgeschichte, 1, 201-240.

McKenna, M. C. 1975. Toward a phylogenetic classification of the Mammalia. Pp. 21-46 in W. P. Luckett \& F. S. Szalay (eds) Phylogeny of the Primates. Plenum Press, New York.

McKenna, M. C. \& Bell, S. K. 1997. Classification of Mammals above the Species Level. New York, Columbia University Press, $631 \mathrm{pp}$.

Miller, E. R., Rasmussen, D. T., Kappelman, J., Friscia, A. R., Muteti, S. N. \& Gutierrez, M. 2015. Ptolemaia from West Turkana, Kenya. Bulletin of the Peabody Museum of Natural History, 56, 81-88.

Mosbrugger, V., Utescher, T. \& Dilcher, D. L. 2005. Cenozoic continental climate evolution of Central Europe. Proceedings of the National Academy of Sciences of the United States of America, 102, 14964-14969.
Mosimann, J. E. \& James, F. C. 1979. New statistical methods for allometry with application to Florida redwinged blackbirds. Evolution, 33, 444-459.

Neal, J. E. 1996. A summary of Paleogene sequence stratigraphy in northwest European and the North Sea. Pp. 15-42 in R. W. Knox \& R. E. Dunay (eds) Correlation of the Early Paleogene in Northwest Europe. Geological Society of London, Special Publications, 101.

Nishihara, H., Satta, Y., Nikaido, M., Thewissen, J. G. M., Stanhope, M. J. \& Okada, N. 2005. A retroposon analysis of Afrotherian phylogeny. Molecular Biology and Evolution, 22, 1823-1833.

Osborn, H. F. 1908. New fossil mammals from the Fayum Oligocene, Egypt. Bulletin of the American Museum of Natural History, 24, 265-272.

Rich, T. H. 1971. Deltatheridia, Carnivora, and Condylarthra (Mammalia) of the early Eocene, Paris Basin, France. University of California Publications in Geological Sciences, 88, 1-72.

Rose, K. D. 2006. The Beginning of the Age of Mammals. John Hopkins University Press, Baltimore, 640 pp.

Russell, D. E. 1964. Les mammifères paléocènes d'Europe. Mémoires du Muséum National d'Histoire Naturelle, 13, $1-324$.

Russell, D. E. \& Godinot, M. 1988. The Paroxyclaenidae (Mammalia) and a new form from the Early Eocene of Palette, France. Paläontologische Zeitschrift, 62, 319-331.

Russell, D. E. \& McKenna, M. C. 1961. Etude de Paroxyclaenus, mammifêre des phosphorites du Quercy. Bulletin de la Sociéte Géologique de France, 3, 274-282.

Savage, D. E., Russell, D. E. \& Louis, P. 1966. Ceratomorpha and Ancylopoda (Perissodactyla) from the Lower Eocene Paris Basin, France. University of California, Publication in Geologic Sciences, 66, 1-38.

Savage, R. J. G. 1965. Fossil mammals of Africa: 19. The Miocene Carnivora of East Africa. Bulletin of the British Museum (Natural History) (Geology), 10, 239-316.

Seiffert, E. R., Simons, E. L., Ryan, T. M., Bown, T. M. \& Attia, Y. 2007. New remains of Eocene and Oligocene Afrosoricida (Afrotheria) from Egypt, with implications for the origin(s) of afrosoricid zalambdodonty. Journal of Vertebrate Paleontology, 27, 963-972.

Simons, E. L. \& Gingerich, P. D. 1974. New carnivorous mammals from the Oligocene of Egypt. Annals of the Geological Survey of Egypt, 4, 157-166.

Simpson, G. G. 1936. A new fauna from the Fort Union of Montana. American Museum Novitates, 873, 1-27.

Smith, R. 2001. Les pantolestidés (Mammalia, Pantolesta) de l'Eocène inférieur de Prémontré (Aisne, France). Palaeovertebrata, 30, 11-35.

Smith, T. \& Smith, R. 2013. A land micro-mammal fauna from the early Eocene marine Egem deposits (NP12, Belgium) and the first occurrence of the peradectid marsupial Armintodelphys outside North America. Geologica Belgica, 16, 302-310.

Solé, F. 2014. New carnivoraforms from the early Eocene of Europe and their bearing on the evolution of the Carnivoraformes. Palaeontology, 57, 963-978.

Solé, F., Falconnet, J. \& Laurent, Y. 2014. New proviverrines (Hyaenodontida) from the early Eocene of Europe; phylogeny and ecological evolution of the Proviverrinae. Zoological Journal of the Linnean Society, 171, 878-917. 
Solé, F., Gheerbrant, E. \& Godinot, M. 2013. Sinopaninae and Arfianinae (Hyaenodontida, Mammalia) from the early Eocene of Europe and Asia; evidence for dispersal in Laurasia around the Paleocene/Eocene boundary and for an unnoticed faunal turnover in Europe. Geobios, 46, 313-327.

Solé, F., Smith, T., Tabuce, R. \& Marandat, B. 2015. New dental elements of the oldest proviverrine mammal from the early Eocene of Southern France support possible African origin of the subfamily. Acta Palaeontologica Polonica, 60, 527-538.

Solé, F., Godinot, M., Laurent, Y., Galoyer, A. \& Smith, T. 2018. The European Mesonychid mammals: phylogeny, ecology, biogeography, and biochronology. Journal of Mammalian Evolution, 25, 339-379

Steurbaut, E., De Coninck, J. \& Van Simaeys, S. 2016. Micropalaeontological dating of the Prémontré mammal fauna (MP10, Prémontré Sands, EECO, early late Ypresian, Paris Basin). Geologica Belgica, 19, 273-280.

Sudre, J. \& Erfurt, J. 1996. Les artiodactyles du gisement yprésien terminal de Prémontré (Aisne, France). Palaeovertebrata, 25, 391-414.

Szalay, F. S. 1969. Mixodectidae, Microsyopidae, and the insectivore-primate transition. Bulletin of the American Museum of Natural History, 140, 193-330.

Teilhard de Chardin, P. 1922. Les mammifères de l'Eocène inférieur français et leurs gisements. Annales de Paléontologie, 11, 1-108.

Teilhard de Chardin, P. 1927. Les Mammifères de 1'Eocène inférieur de la Belgique. Mémoires du Musée royal d'Histoire naturelle de Belgique, 36, 1-33.

Tobien, H. 1969. Kopidodon (Condylarthra, Mammalia) aus dem Mitteleozän (Lutetium) von Messel bei Darmstadt (Hessen). Notizblatt des Hessischen Landesamtes für Bodenforschung zu Wiesbaden, 97, 7-37.
Van Valen, L. 1965. Paroxyclaenidae, an extinct family of Eurasian Mammals. Journal of Mammalogy, 46, 388-397.

Vanhove, D., Stassen, P., Speijer, R. \& Steurbaut, E. 2011. Assessing paleotemperature and seasonality during the early Eocene climatic optimum (EECO) in the Belgian Basin by means of fish otolith stable $\mathrm{O}$ and $\mathrm{C}$ isotopes. Geologica Belgica, 14, 143-157.

Weitzel, K. 1933. Kopidodon macrognathus Wittitch, ein Raubtier a us dem Mitteleozän von Messel. Notizblatt des Vereins fur Erdkunde und der Hessischen Geologischen Landesanstalt zu Darmstadt, 14, 81-88.

Wittich, E. 1902. Cryptopithecus macrognathus n. spec., ein neuer Primate aus den Braunkohlen von Messel. Centralblatt für Mineralogie, Geologie und Paläontologie, 10, 289-294.

Woodburne, M. O., Gunnell, G. F. \& Stucky, R. K. 2009. Climate directly influences Eocene mammal fauna dynamics in North America. Proceedings of the National Academy of Sciences of the United States of America, 106, 13399-13403.

Yans, J., Marandat, B., Masure, E., Serra-Kiel, J., Schnyder, J., Storme, J.-Y., Marivaux, L., Adnet, S., Vianey-Liaud, M. \& Tabuce, R. 2014. Refined bio(benthic foraminifera, dinoflagellate cysts) and chemostratigraphy $\left(\delta^{13} \mathrm{C}_{\mathrm{org}}\right)$ of the earliest Eocene at albas-Le clot (Corbières, France): implications for mammalian biochronology in southern Europe. Newsletters on Stratigraphy, 47, 331-353.

Zachos, J. C., Dickens, G. R. \& Zeebe, R. E. 2008. An early Cenozoic perspective on greenhouse warming and carboncycle dynamics. Nature, 451, 279-283.

Associate Editor: Pip Brewer 